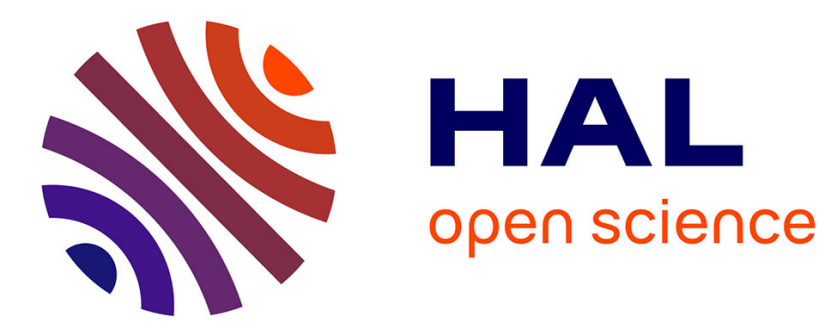

\title{
Mechanistic View on Efficient Photodetection by Solvothermally Reduced Graphene Oxide
}

\author{
Mustaque A. Khan, Karuna K Nanda, Saluru B Krupanidhi
}

\section{To cite this version:}

Mustaque A. Khan, Karuna K Nanda, Saluru B Krupanidhi. Mechanistic View on Efficient Photodetection by Solvothermally Reduced Graphene Oxide. Journal of Materials Science: Materials in Electronics, 2017, 28 (19), pp.14818-14826. 10.1007/s10854-017-7352-1 . hal-02480186

\section{HAL Id: hal-02480186 \\ https://hal.science/hal-02480186}

Submitted on 15 Feb 2020

HAL is a multi-disciplinary open access archive for the deposit and dissemination of scientific research documents, whether they are published or not. The documents may come from teaching and research institutions in France or abroad, or from public or private research centers.
L'archive ouverte pluridisciplinaire HAL, est destinée au dépôt et à la diffusion de documents scientifiques de niveau recherche, publiés ou non, émanant des établissements d'enseignement et de recherche français ou étrangers, des laboratoires publics ou privés. 


\title{
Mechanistic View on Efficient Photodetection by
}

\section{Solvothermally Reduced Graphene Oxide}

\author{
Mustaque A. Khan, ${ }^{\dagger}$ Karuna K. Nanda ${ }^{\dagger}$ and Saluru B. Krupanidhi ${ }^{\dagger}{ }^{\dagger}$ \\ ${ }^{\dagger}$ Materials Research Centre, Indian Institute of Science, Bangalore 560012, India \\ Corresponding Author \\ *E-mail:sbk@mrc.iisc.ernet.in
}

\section{Abstract}

Despite of the progress, graphene based photodetectors still suffer from very low responsivity. Tunable optical properties and ease of preparation of has made reduced graphene oxide (RGO) a promising substitute material for graphene in many optoelectronic applications. We have studied solvothermal reduction of graphene oxide in ethylene glycol and photodetection properties of as made RGO based devices. In near infrared region a responsivity value as high as $0.78 \mathrm{~A} . \mathrm{W}^{-1}$ with an external quantum efficiency of $62 \%$ has been achieved at a bias of only $0.5 \mathrm{~V}$. Corresponding values in ultraviolet region are $0.27 \mathrm{~A} . \mathrm{W}^{-1}$ and $102 \%$. Few layer nature and increased reduction can increase absorption efficiency of RGO. Defects in graphene sheets in RGO create mid-gap states band (MGB). MGB can generate gain in photocurrent by preventing quick recombination of photogenerated charge carriers. Increased absorption and longer carrier 
lifetime enhances the performance of RGO based devices. Also a linear variation of photocurrent in RGO with temperature indicates its potential as temperature sensor.

Keywords: reduced graphene oxide; mid-gap states band; photodetector; temperature sensor.

\section{Introduction}

Infrared detectors are used in LiDAR sensors for self-driving cars, remote controlled devices, gas leak detection, Astrology, missile technology etc [1]. UV photodetectors are used in secure space communication, air pollution level detection, ozone sensing $\left(\mathrm{O}_{3}\right)$ and ozone layer leak detection. Commercial photodetectors are very costly and many of them uses toxic elements like arsenic (As) [2], mercury $(\mathrm{Hg})$ [3], lead $(\mathrm{Pb})$ [4], etc. Zero band gap of graphene has made it a potential material for broadband photodetector. But due to poor light absorption (2.3\%) [5] and fast recombination of photoexcited carriers [6,7], graphene based photodetectors show very low responsivity (few $\mathrm{mA} \cdot \mathrm{W}^{-1}$ ). Efforts have been made to improve the absorption property and enhance responsivity by decorating graphene with plasmonic nano-structures [8], introducing graphene in a micro-cavity [9]. Researchers have tried to enhance responsivity by incorporating defects for longer carrier lifetime [10]. Despite these efforts, responsivity value of most of the graphene based photodetectors remains within few tens of mA.W ${ }^{-1}$ range.

Recently, graphene oxide (GO) and RGO have gained a lot of attention among researchers in almost every scientific field. GO and RGO have found application in bio-imaging [11], catalyzing reactions [12, 13], surface-enhanced Raman spectroscopy (SERS) [14], water purification [15], energy storage [16] and oxygen reduction reaction [17]. Tunable optical 
properties and ease of preparation have made RGO a low cost but efficient optoelectronic material. RGO based photodetectors can evince broad band photoresponse [18-21].

We have prepared RGO by solvothermal reduction of GO in ethylene glycol and explored its photodetection properties. Responsivity value is quite high compared to most the graphene or RGO based photodetectors. EQE value reaches $62 \%$ and $102 \%$ under NIR and UV irradiation, respectively. We have noticed that $\mathrm{EQE}$ variation with $\mathrm{C} / \mathrm{O}$ ratio of $\mathrm{RGO}$ is superlinar in nature. In order to investigate the underlining reason behind higher responsivity (and EQE) values and the superlinear variation of $\mathrm{EQE}$ with $\mathrm{C} / \mathrm{O}$ ratio, we have carried out temperature dependent photocurrent measurement from $\sim 10 \mathrm{~K}$ to $\sim 300 \mathrm{~K}$. This measurement shows photocurrent decrease linearly with increasing temperature. Thus temperature-dependent measurement indicates presence of mid-gap state band (MGB) in reduced graphene oxide and also reveals its potential as temperature sensor.

\section{Experimental Section:}

\section{Materials and methods}

Graphite (flakes) was purchased from Sigma Aldrich. Sulfuric acid $\left(\mathrm{H}_{2} \mathrm{SO}_{4}\right)$ and potassium permanganate $\left(\mathrm{KMnO}_{4}\right)$ were purchased from Fisher Scientific. Ethylene glycol, hydrochloric acid $(\mathrm{HCl})$ and sodium nitrate $\left(\mathrm{NaNO}_{3}\right)$ were purchased from SDFCL. Ethanol was bought from local supplier. Purity of all the chemicals is more than $99 \%$.

\section{Synthetic procedures}

Hummers' method is used for oxidation of graphite flakes to graphitic oxide [22]. In brief, $2 \mathrm{~g}$ graphite and $1 \mathrm{~g}$ of $\mathrm{NaNO}_{3}$ are taken in a $500 \mathrm{ml}$ round bottom flask. Then $50 \mathrm{ml}$ conc. $\mathrm{H}_{2} \mathrm{SO}_{4}$ is 
added to the mixture. The mixture is stirred for 30 minutes in an ice bath. After that $6 \mathrm{~g} \mathrm{KMnO} 4$ is slowly added into the mixture with an additional stirring of $1 \mathrm{~h}$. Round bottom flask is taken out from ice bath and heated for $2 \mathrm{~h}$ at $35^{\circ} \mathrm{C}$. Deionized water $(80 \mathrm{ml})$ is added to the brownish green paste and the reaction mixture is heated at $98{ }^{\circ} \mathrm{C}$ for 15 minutes. Then the reaction mixture is cooled to room temperature. Again deionized water $(280 \mathrm{ml})$ is added to it followed by $\sim 50 \mathrm{ml}$ of $\mathrm{H}_{2} \mathrm{O}_{2}(30 \%)$. The deep brown product (GO) is first washed with diluted $\mathrm{HCl}$ and then with deionized water. The as-prepared $\mathrm{GO}$ is then dried at $50^{\circ} \mathrm{C}$ for 24 hours.

Reduction of GO is carried out by solvothermal method in presence of ethylene glycol. At first $80 \mathrm{mg}$ of $\mathrm{GO}$ is added to $40 \mathrm{ml}$ of ethylene glycol and sonicated for $3 \mathrm{~h}$ in order to exfoliate GO [23]. Then GO dispersion is transferred into a $50 \mathrm{ml}$ Teflon lined autoclave and solvothermal reduction is carried out for $3,6,12$ and $24 \mathrm{~h}$ at $180^{\circ} \mathrm{C}$. The products are centrifuged at $5000 \mathrm{rpm}$ for 5 minutes and washed with ethanol. Then RGOs are dried under vacuum for overnight. Products of 3, 6, 12 and $24 \mathrm{~h}$ reductions are named as RGO1, RGO2, RGO3 and RGO4.

\section{Characterization}

Scanning electron microscopy (SEM) and transmission electron microscopy (TEM) images are captured with ZEISS's GEMINI ULTRA 55 FE-SEM and FEI Tecnai F30 S-TWIN TEM, respectively. Absorption and infrared (IR) spectra have been acquired using PerkinElmer UV/VIS/NIR Lambda 750 spectrometer and Bruker FTIR instrument, respectively. RigakuSmartLab X-ray diffractometer with $\mathrm{Cu} \mathrm{K} \alpha$ as $\mathrm{X}$ - ray source is used for X-ray diffraction (XRD) studies. Raman spectra have been recorded using LabRAM HR system with $532 \mathrm{~nm}$ laser as excitation source. KRATOS ANALYTICAL's AXIS Ultra photoelectron spectrometer with $\mathrm{Al} \mathrm{K} \alpha$ as X-ray source is used for X-ray photoelectron spectroscopy (XPS) studies. 


\section{Device Fabrication}

Silver electrodes $(200 \mathrm{~nm})$ are deposited by thermal evaporation on clean quartz substrate. A thin copper wire is used as mask to create $\mathrm{a} \sim 95 \mu \mathrm{m}$ wide channel between the electrodes (figure $\mathrm{S} 1$ ). For device fabrication purpose RGO dispersions have been made in toluene by sonication (4.8 mg of RGO, $150 \mu \mathrm{L}$ of toluene). Then RGO dispersions are drop casted on the channel between the electrodes and dried at $\sim 35^{\circ} \mathrm{C}$ for 45 minutes. A CNI's MDL-III $1550 \mathrm{~nm}$ laser with an optical coupler (radius is $2 \mathrm{~mm}$ ) has been used as the IR source. Melles Griot $325 \mathrm{~nm} \mathrm{He}-\mathrm{Cd}$ laser with a beam diameter of $1.4 \mathrm{~mm}$ has been used as UV source. Electrical studies have been carried out using Tektronix Keithley 2400 source measure instrument.

\section{Results and Discussion}

XRD (figure S2) studies of GO shows a peak at a $2 \theta=11.80^{\circ}$ which corresponds to an interlayer distance of $7.49 \AA$. This large interlayer distance is due to the formation of hydroxyl, epoxy and carboxyl groups on graphene sheets during oxidation of graphite flakes [24]. After reduction, the peak position shifts around graphitic peak at $2 \theta=24.96^{\circ}$ that corresponds to an interlayer distance of $3.56 \AA$. Decrease in interlayer distance is due to the removal of many oxygen containing functional groups during reduction process. Broad peak of RGO 3 also indicates few layer nature of RGO. SEM and TEM images show thin flake like structure of RGO (Figure $1 \mathrm{a}, \mathrm{b}$ and c). HRTEM image in figure 1d shows few layer nature of RGO. Average distance between the layers is $3.6 \AA$ which is in excellent agreement with XRD result. SAED pattern (figure 1d inset) shows hexagonal nature of the RGO sheet. The outer diffraction spots correspond to (2110) planes and the inner diffraction spots corresponds to (1100) planes. 


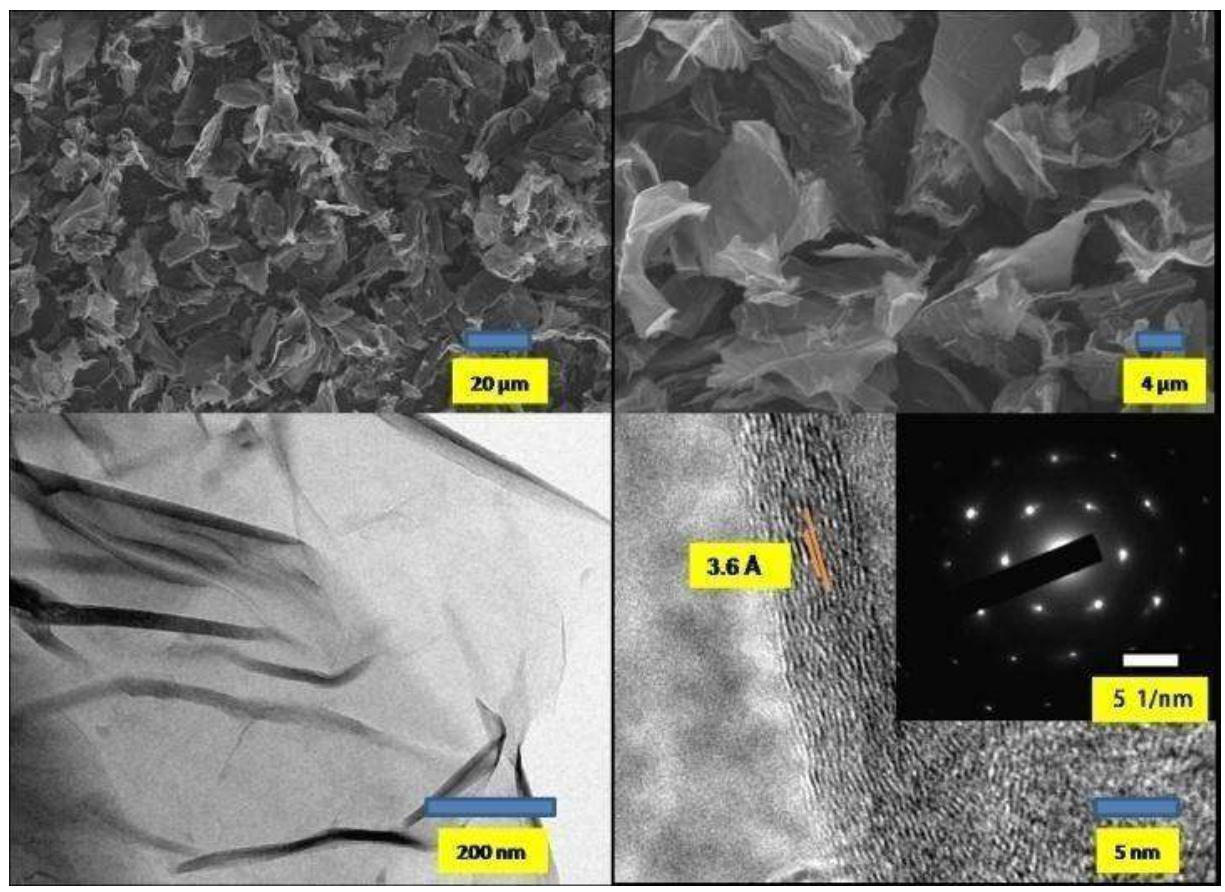

Fig. 1: (a) and (b) SEM images of RGO3. (c) TEM image and (d) HRTEM image of RGO3. Inset shows the SAED pattern.

Absorption spectra of $\mathrm{GO}$ and RGOs are taken from N-methyl-2-pyrrolidone (figure 2a). Absorption increases with reduction time. This indicates increase in absorption cross-section with reduction time. FTIR spectra (figure S3) indicate that after reduction many hydroxyl, carboxyl, epoxy groups are removed. A decreased alkane $\mathrm{C}-\mathrm{H}$ stretching intensity has been recorded after reduction, where as $\mathrm{C}-\mathrm{H}$ in plane bending intensity increases. It can also be concluded from FTIR spectra also that aromaticiy has been restored significantly after reduction. XPS survey spectra of GO and RGOs shows increase in $\mathrm{C} / \mathrm{O}$ after reduction (figure $\mathrm{S} 4 \mathrm{a}, \mathrm{b}$ ). $\mathrm{C} 1 \mathrm{~s}$ XPS spectrum of GO in Figure 2b shows high degree of oxidation. Four components represent carbon atoms in different functional groups. The peak around $284.48 \mathrm{eV}$ and $286.49 \mathrm{eV}$ corresponds to ring carbons which are not oxygenated and the $\mathrm{C}-\mathrm{O}$ bonded carbon atoms respectively [25]. Peak at $288.30 \mathrm{eV}$ and $290.31 \mathrm{eV}$ refers to carbonyl $(-\mathrm{C}=\mathrm{O})$ carbon and 
carboxyl carbon $(-\mathrm{COOH})$. It can be noticed from figure $2 \mathrm{c}$ that after reduction the relative intensity of oxygen functionalized carbon atoms decreases. Atomic percentage of carbon and oxygen in GO and different RGOs has been shown in Table 1.

(a)

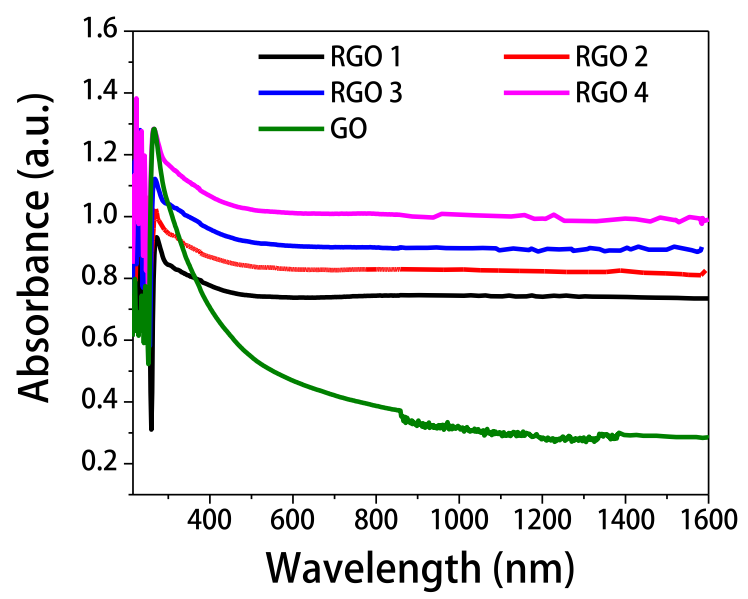

(c)

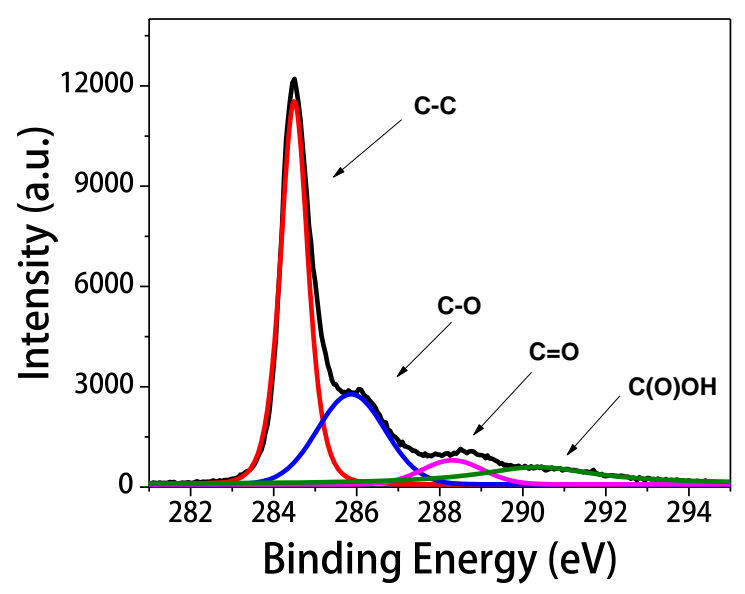

(b)

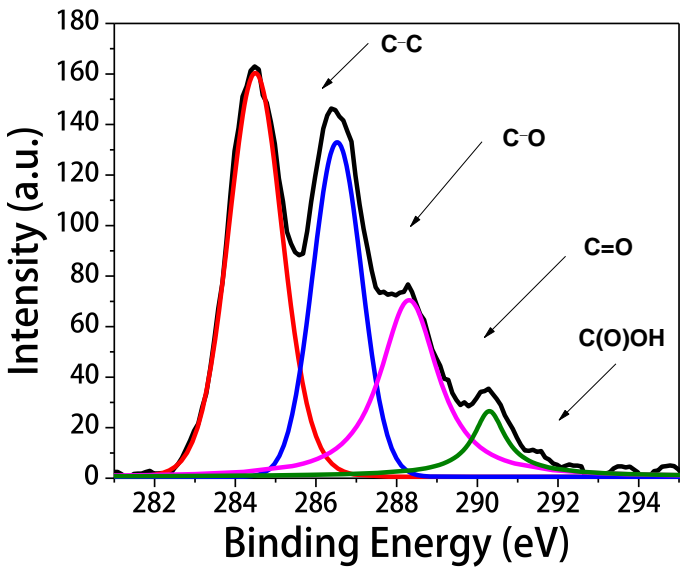

(d)

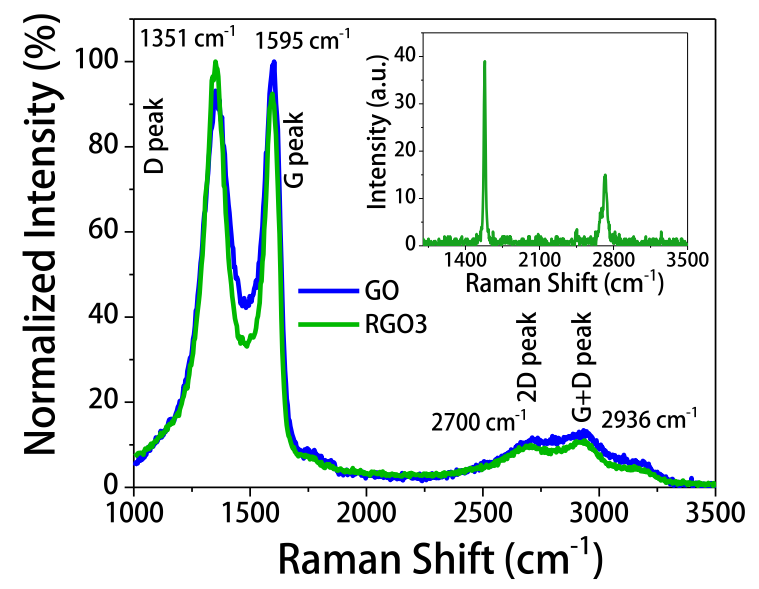

Fig. 2: (a) Absorption spectra of GO and RGOs; (b) and (c) XPS C1s spectra of GO and RGO3, respectively; (d) Raman spectra of GO, RGO3 and graphite (inset). 
Table 1: Carbon and Oxygen percentage in GO and RGO

\begin{tabular}{|l|l|l|l|}
\hline Sample & $\mathrm{C} \%$ & $\mathrm{O} \%$ & $\mathrm{C} / \mathrm{O}$ \\
\hline GO & 66.27 & 33.73 & 1.96 \\
\hline RGO 1 & 83.75 & 16.25 & 5.15 \\
\hline RGO 2 & 84.25 & 15.75 & 5.35 \\
\hline RGO 3 & 85.12 & 14.88 & 5.72 \\
\hline RGO 4 & 86.37 & 13.63 & 6.34 \\
\hline
\end{tabular}

Raman spectra of graphite, GO and RGO have been shown in figure 2d. Graphite has two most prominent peaks namely $\mathrm{G}$ peak $\left(\sim 1595 \mathrm{~cm}^{-1}\right)$ and 2D peak $\left(\sim 2700 \mathrm{~cm}^{-1}\right)$ [26]. Raman spectrum of GO and RGOs shows an additional strong peak at $\sim 1351 \mathrm{~cm}^{-1}$ known as D peak and a less intense broad peak $2936 \mathrm{~cm}^{-1}$ known as G+D peak [27]. G peak corresponds to $\mathrm{E}_{2 \mathrm{~g}}$ mode of carbon atoms vibration [28]. $\mathrm{D}$ peak which (corresponds to $\mathrm{A}_{1 \mathrm{~g}}$ mode) is absent in pure graphene and graphite appears if defects are present in the structure [28]. Thus Raman spectrum indicates presence of large amount of defects on the graphene sheets of GO and RGO. We have observed that $\mathrm{I}_{\mathrm{D}} / \mathrm{I}_{\mathrm{G}}$ value is very much position dependent for both $\mathrm{GO}$ and RGO. In the reported spectra, $\mathrm{I}_{\mathrm{D}} / \mathrm{I}_{\mathrm{G}}$ value is 2.20 and 1.99 for $\mathrm{GO}$ and RGO3, respectively.

Photodetection experiments have been performed with $1550 \mathrm{~nm}$ IR laser. Temporal photoresponses for RGO 2 and RGO 3 with different intensity (at $0.3 \mathrm{~V}$ ) have been presented in figure $3 \mathrm{a}$ and $\mathrm{b}$, respectively. These results show that our devices response to infrared radiation immediately. 
(a)

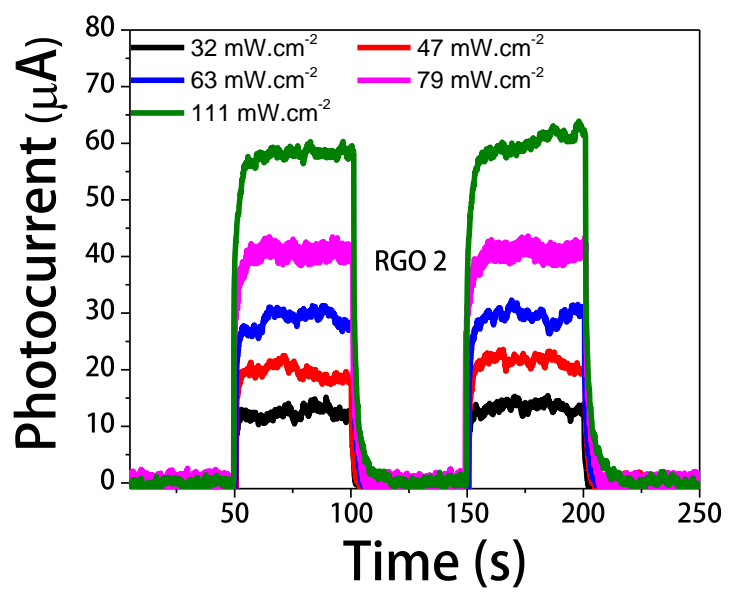

(b)

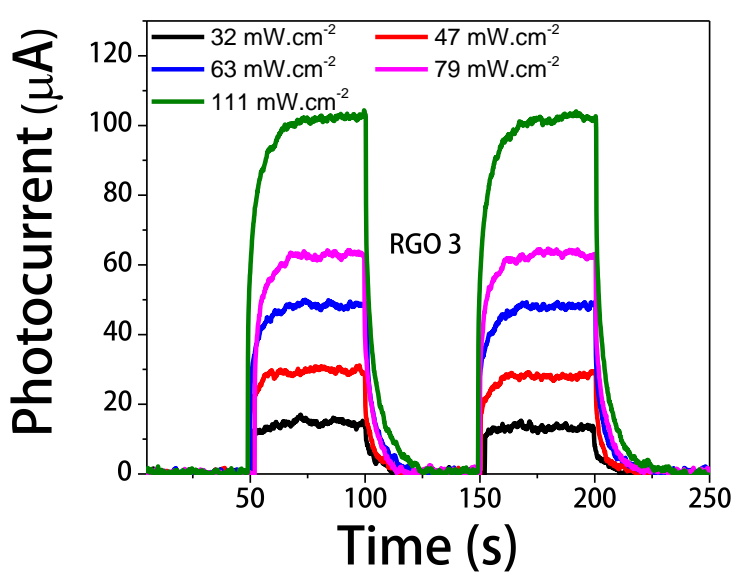

(c)

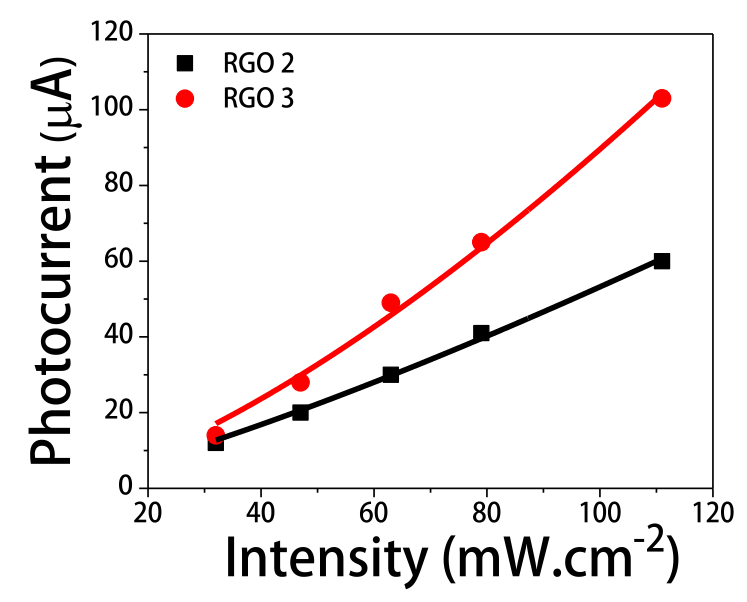

Fig. 3: Temporal photoresponse of (a) RGO 2 and (b) RGO 3 at different intensities of $1550 \mathrm{~nm}$ IR radiation and at a constant bias of $0.3 \mathrm{~V}$. (c) Variation of photocurrent with IR $(1550 \mathrm{~nm})$ power for RGO2 and RGO 3.

It also shows that photocurrent increases with increased radiation intensity. Variation of photocurrent with intensity has been plotted in figure $3 \mathrm{c}$. The values are fitted with the equation,

$$
I_{P h}=\alpha * I_{L}^{\beta}
$$


where $\boldsymbol{I}_{\boldsymbol{P h}}$ is photocurrent, $\boldsymbol{I}_{\boldsymbol{L}}$ is intensity of radiation, $\boldsymbol{\alpha}$ and $\boldsymbol{\beta}$ are constants [29]. The value of $\boldsymbol{\beta}$ is 1.25 and 1.45 for RGO2 and RGO3, respectively. Non-unity of $\boldsymbol{\beta}$ values implies complex processes of exciton generation, trapping, scattering and recombination [29]. Figures S5 a, b show temporal photoresponse with variation of voltage at a constant IR intensity of $79 \mathrm{~mW} \cdot \mathrm{cm}^{-2}$. Variation of photocurrent with voltage at a constant intensity has been plotted in figure S5c. The values are well fitted with straight line indicating linear variation of photocurrent with bias voltage. On-off measurements over 20 cycles ensure the reproducibility of photocurrent measurement (figure S6).

Several mechanisms have been proposed regarding generation of photocurrent in graphene and RGO. As the contacts are nearly ohmic in nature, there is no sufficient built in field to separate photogenerated electron and holes and we have observed zero photocurrent at zero bias. Another proposed mechanism of photocurrent generation is photo-thermoelectric effect. This effect comes into action when the illumination is asymmetric but in our case illumination is symmetric in nature. In few cases, photocurrent generation have been assigned to bolometric effect. Bolometric effect is the reduction of resistance due temperature rise caused by illumination. We have carried out photocurrent measurements with a continuous diode laser. Continuous illumination may increase the temperature of RGO. In order to confirm or eliminate bolometric effect, we have used a chopper for photodetection measurement. Temperature rise $(\Delta \mathrm{T})$ due to optical heating decreases with increasing chopping frequency as increased chopping leads to better heat dissipation. Hence, the bolometric current should decrease with increasing chopping. However, we observed no significant variation in photocurrent with the variation of chopping frequency (figure S7). Thus, we conclude that photocurrent is photovoltaic in nature. 
I-V measurement under dark and UV illumination (figure S8a) indicates that under UV illumination current in the device increases. Photocurrent measurement with $1550 \mathrm{~nm}$ laser for different RGOs at $0.5 \mathrm{~V}$ and $79 \mathrm{~mW} . \mathrm{cm}^{-2}$ has been shown in figure 4a. Also photocurrent measurement with $325 \mathrm{~nm}$ laser has been carried out at an intensity of $519.6 \mathrm{~mW} . \mathrm{cm}^{-2}$ at $0.5 \mathrm{~V}$ and produced in figure S8b. External responsivity $(\mathbf{R})$ of a photodetector is described as photocurrent generation per unit incident radiation per unit area and is given by

$$
\boldsymbol{R}=\boldsymbol{I}_{\boldsymbol{P h}} /\left(\boldsymbol{I}_{L} * \boldsymbol{A}\right)
$$

where $\boldsymbol{I}_{\boldsymbol{P}}$ is the photocurrent, $\boldsymbol{I}_{\boldsymbol{L}}$ is the light intensity and $\boldsymbol{A}$ is the effective area of the device [30, 31]. The external quantum efficiency $(\boldsymbol{E} \boldsymbol{Q E})$ is determined by the ratio of the number charge carrier collected by the device to the number of photons irradiated on the effective area (A) of the device and can be calculated from

$$
E Q E=h c R / e \lambda
$$

where $\boldsymbol{h}$ is the Plank's constant, $\boldsymbol{c}$ is the velocity of light, $\boldsymbol{e}$ is the electronic charge and $\boldsymbol{\lambda}$ is the wavelength of incident radiation [30, 31]. Responsivity and EQE values of our photodetectors are summarized in table 2.

EQE values of RGOs have been plotted with $\mathrm{C} / \mathrm{O}$ ratio in figure $4 \mathrm{~b}$ and figure $\mathrm{S} 8 \mathrm{c}$ for NIR and UV irradiation respectively. The variation of EQE is well fitted with the equation

$$
\boldsymbol{E Q E}=\boldsymbol{\kappa} * \boldsymbol{x}^{\gamma}
$$

where $\boldsymbol{x}=\mathrm{C} / \mathrm{O}$ ratio and $\kappa$ and $\boldsymbol{\gamma}$ are constants. $\boldsymbol{\gamma}$ value obtained from the fitting is 6.65 and 8.39 for NIR and UV irradiation respectively, indicating a superlinear variation of EQE with $\mathrm{C} / \mathrm{O}$ 
ratio. Responsivity value of the graphene and RGO based photodetectors mostly remains low for commercial use (few tens of $\mathrm{mA} \cdot \mathrm{W}^{-1}$ ). The responsivity and EQE values achieved by our photodetectors are much higher than most graphene or RGO based photodetectors.

(a)

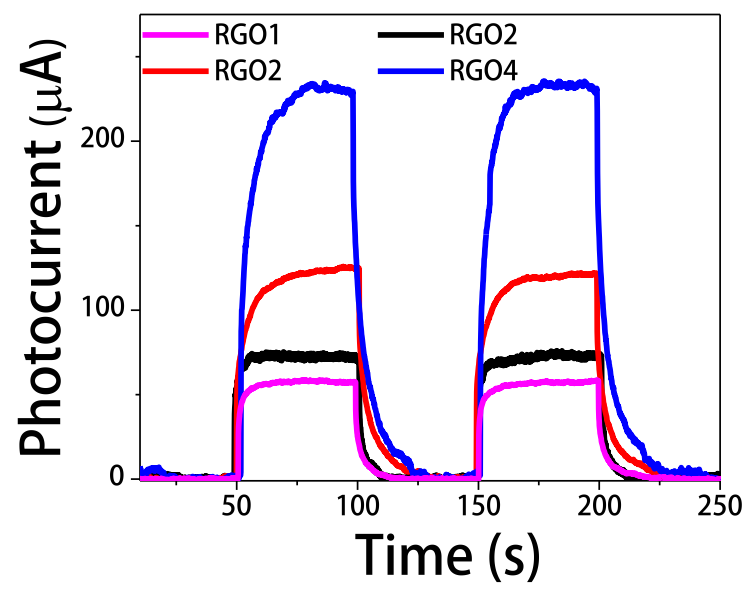

(b)

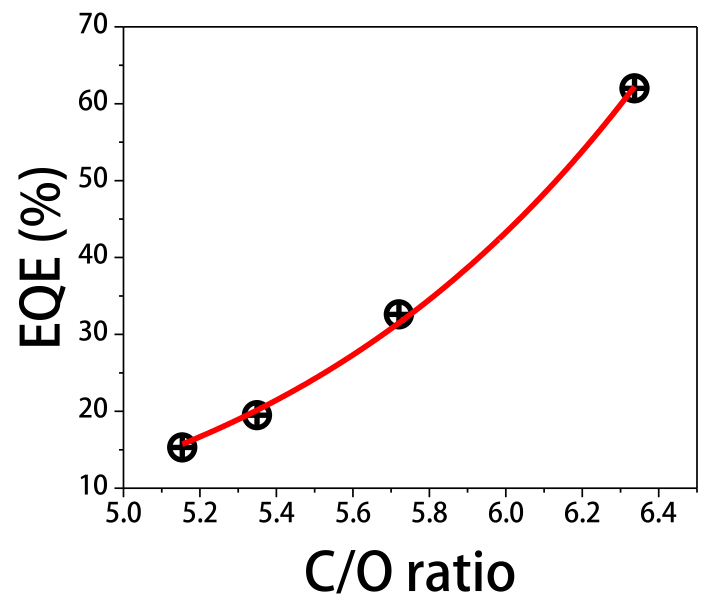

Fig. 4: (a) Temporal photoresponse of different RGOs at bias of $0.5 \mathrm{~V}, \lambda=1550 \mathrm{~nm}$ and $\mathrm{I}_{\mathrm{L}}=79 \mathrm{~mW} \cdot \mathrm{cm}^{-2}$, and (b) Variation of EQE with $\mathrm{C} / \mathrm{O}$ ratio of RGOs.

Table 2: Responsivity and external quantum efficiency of different RGO based photodetectors $\left(\mathrm{V}_{\mathrm{SD}}=0.5\right.$ $\mathrm{V} ; \mathrm{I}_{\mathrm{L}}(1550 \mathrm{~nm})=79 \mathrm{~mW} \cdot \mathrm{cm}^{-2}$ and $\left.\mathrm{I}_{\mathrm{L}}(325 \mathrm{~nm})=519.6 \mathrm{~mW} \cdot \mathrm{cm}^{-2}\right)$.

\begin{tabular}{|l|c|c|c|c|}
\hline Sample & \multicolumn{2}{|c|}{ R (A/W) } & \multicolumn{2}{c|}{ EQE (\%) } \\
& $1550 \mathrm{~nm}$ & $325 \mathrm{~nm}$ & $1550 \mathrm{~nm}$ & $325 \mathrm{~nm}$ \\
\hline RGO 1 & $0.19 \pm 0.03$ & $0.052 \pm 0.002$ & $15.3 \pm 2.3$ & $19.84 \pm 1$ \\
\hline RGO 2 & $0.24 \pm 0.03$ & $0.068 \pm 0.005$ & $19.2 \pm 2.4$ & $25.94 \pm 1.75$ \\
& & & & \\
\hline RGO 3 & $0.41 \pm 0.05$ & $0.104 \pm 0.008$ & $32.8 \pm 4.0$ & $39.68 \pm 2.75$ \\
\hline RGO 4 & $0.78 \pm 0.06$ & $0.268 \pm 0.01$ & $62.4 \pm 4.8$ & $102.25 \pm 3.25$ \\
\hline
\end{tabular}




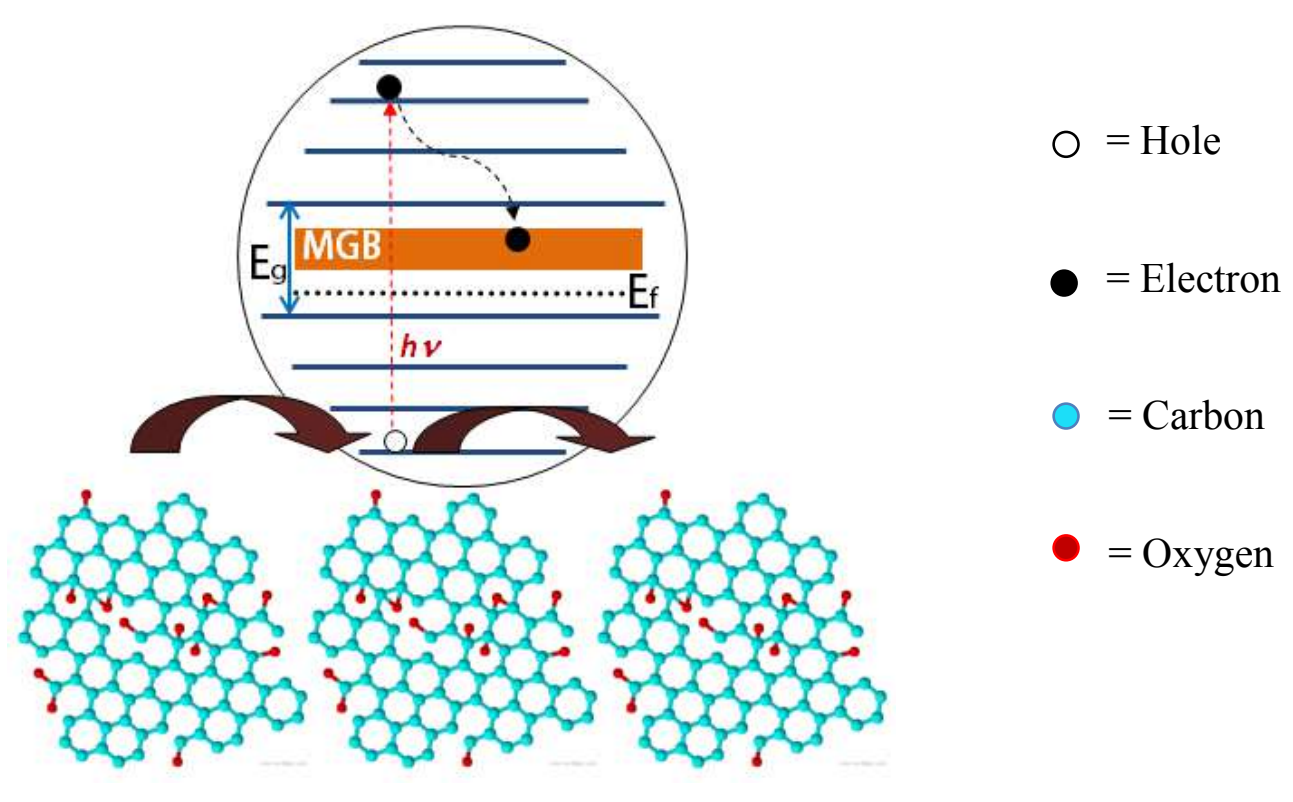

Schematic 1: Illustration of photogenerated electron trapping by mid-gap state band and hole hopping.

I-V characteristic at low temperature (Figure S9a) shows Coulomb blocked effect. The best linear fit of $\ln \left(\mathrm{I}_{\mathrm{d}}\right)$ is obtained with $\mathrm{T}^{-1 / 4}$ (Figure $\mathrm{S} 9 \mathrm{~b}$ ) indicating hopping in all direction between the reduced graphene oxide sheets. Few layer nature of RGO enhances the light absorption which leads to higher number of exciton generation [32]. The increase of C/O ratio in RGO leads to decreased band gap [33] and hence increased absorbance. In spite of strong absorbance, photocurrent generation would still be lower if the photogenerated electron and holes recombine very fast. During its preparation several kinds of defects get incorporated into RGO sheets (Raman D-peak is an indicative of defects in graphene sheets). Impurity, cracks, vacancies, boundaries, corrugated morphology lead to the formation of mid-gap state band (MGB) in graphene [34-36]. MGBs can increase the lifetime of photo-excited electron-hole by trapping the charge carriers which prevents recombination [37]. Thus, during the lifetime of trapped electron, 
hole can circulate many times generating a gain in photocurrent before recombination (Schematic 1) [38, 39]. With the increase of incident intensity, number of photogenerated holes increases leading to higher gain and $\boldsymbol{\beta}>1$. Similarly, high $\boldsymbol{\gamma}$ value can be due to the increased absorption in $\mathrm{RGO}$ with increase in $\mathrm{C} / \mathrm{O}$ ratio. Increased absorption generates more photogenerated holes, which means more gain in photocurrent. Higher $\boldsymbol{\gamma}$ in UV region is also due to increased absorption in UV region compared to infrared region. Overall, high value of $\boldsymbol{\beta}$ and $\boldsymbol{\gamma}$ are assisted by the presence of MGB.

(a)

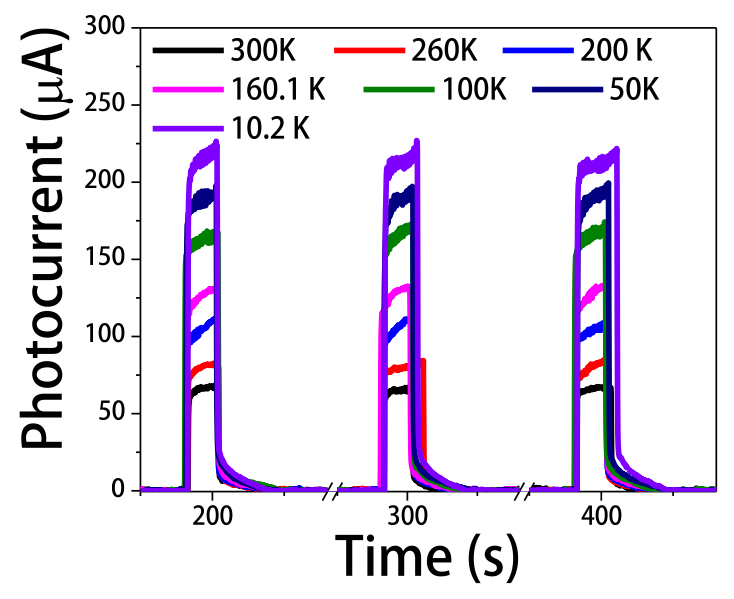

(b)

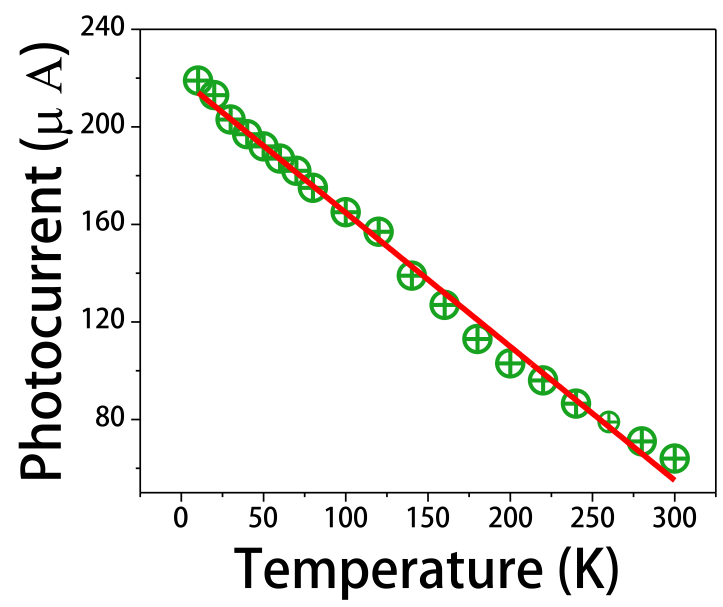

Fig. 5: (a) Temporal photoresponse at different temperature for RGO $2(\lambda=632 \mathrm{~nm})$, and (b) photocurrent as a function of temperature.

In order to realize the presence of MGB, temperature-dependent photoresponse have been investigated (with He-Ne laser) and temporal response curves are presented in figure 5a. As indicated above, MGB can trap electrons and trapping is more at low temperature. As a result, the photocurrent is expected to increase and our experimental results corroborating the presence of MGB. Interestingly, the variation of photocurrent with temperature is almost linear in a wide 
temperature range $(10-300 \mathrm{~K})$ which advocates the potential application as temperature sensor (Figure 5b).

Rise and decay kinetics of photocurrent have also been studied by fitting the exponential curves (figure 6 for NIR and figure S10 for UV irradiation). Rise and decay of photocurrent are fitted by the equation

$$
I_{t}=I_{f}+A_{1} * \exp \left(-t / \tau_{1}\right)+A_{2} * \exp \left(-t / \tau_{2}\right)
$$

where $\boldsymbol{I}_{\boldsymbol{t}}$ is photocurrent at any time $\boldsymbol{t}$ and $\boldsymbol{I}_{\boldsymbol{f}}$ is the final photocurrent, $\boldsymbol{A}_{\boldsymbol{1}}$ and $\boldsymbol{A}_{2}$ are constants (depends on incident light intensity), and $\tau_{1}$ and $\tau_{2}$ are time constants [30, 31, 40]. Lower the value of constants $\tau_{1}, \tau_{2}$, faster is the process. Time constants for rise and decay for different RGOs have been listed in table 3 and table $\mathrm{S} 1$, for 1550 and $325 \mathrm{~nm}$ respectively. Smaller value of time constants compared to many other graphene or RGO based photodetectors indicates faster operation of our devices.

(a)

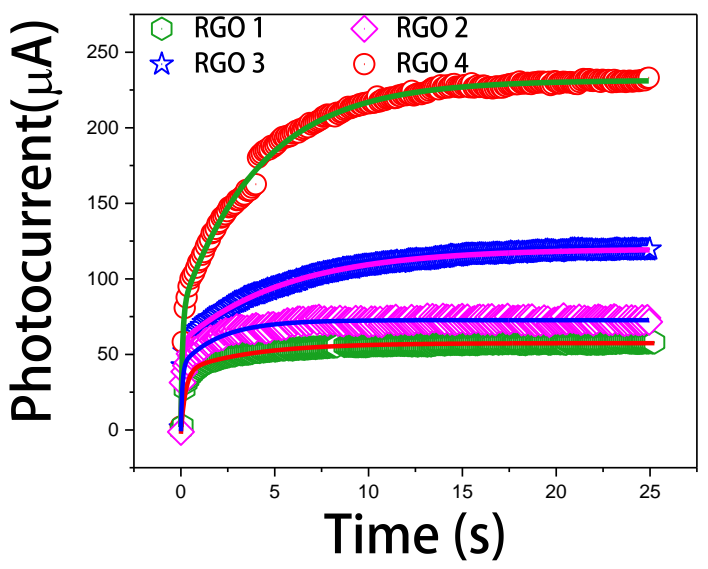

(b)

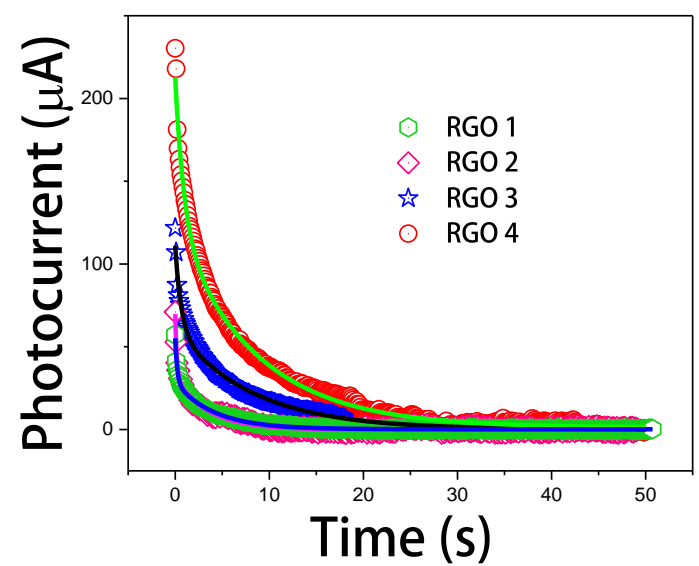

Fig. 6: (a) Rise and (b) decay of photocurrent at an intensity of $79 \mathrm{~mW} \cdot \mathrm{cm}^{-2}$ at $0.5 \mathrm{~V}$ bias $(\lambda=1550 \mathrm{~nm})$ and their exponential fittings. 
Table 3: Time constants for rise and decay of photocurrent for NIR $(1550 \mathrm{~nm})$ irradiation of $79 \mathrm{~mW} . \mathrm{cm}^{-2}$ at $0.5 \mathrm{~V}$ applied bias.

\begin{tabular}{|c|c|c|c|c|}
\hline Sample & \multicolumn{2}{|c|}{ Rise (s) } & \multicolumn{2}{c|}{ Decay (s) } \\
& \multicolumn{2}{|c}{$\tau_{1}$} & $\tau_{2}$ & $\tau_{1}$ \\
& & & $\tau_{2}$ \\
\hline RGO 1 & $0.25 \pm 0.01$ & $3.76 \pm 0.14$ & $0.22 \pm 0.01$ & $4.09 \pm 0.04$ \\
& & & & \\
\hline RGO 2 & $0.08 \pm 0.01$ & $2.11 \pm 0.07$ & $0.18 \pm 0.01$ & $3.51 \pm 0.09$ \\
\hline RGO 3 & $0.09 \pm 0.01$ & $5.64 \pm 0.05$ & $0.63 \pm 0.03$ & $8.18 \pm 0.11$ \\
\hline RGO 4 & $0.09 \pm 0.01$ & $4.26 \pm 0.04$ & $0.95 \pm 0.04$ & $8.52 \pm 0.12$ \\
\hline
\end{tabular}

A comparison of the characteristics of graphene (or reduced graphene oxide) based photodetectors has been provided in table 4. In most of cases graphene or RGO based photodetectors exhibits photoresponse as low as few ten of $\mathrm{mA} . \mathrm{W}^{-1}$. These low values of responsivity have been attributed to lower light absorbance and faster carrier recombination in graphene. Wrinkle formation in graphene has significantly increased the photoresponse of CVD grown few-layer graphene [10]. Asymmetric electrode enhances the collection of both photogenerated electron and holes and leads to 15-fold increase in responsivity [41]. Microcavity increases light absorption in graphene and enhances responsivity value significantly [9]. Integration of graphene with silicon waveguide enhances the light absorption and leads to a significant increase in responsivity to an astounding value of $\sim 0.1 \mathrm{~A}^{-\mathrm{W}^{-1}}$ [42]. Hydrazine reduction of graphitic oxide follows a fast kinetics and the prepared RGO exhibits lower responsivity [31]. Thermal reduction of GO at lower processing temperature can control the amounts of defects in RGO. Defect Controlled thermal reduction processes have helped to increase the responsivity of reduced graphene to a value of $\sim 0.7 \mathrm{~A} . \mathrm{W}^{-1}$ in NIR region $[30,43]$. 
Implication of asymmetric electrodes can increase UV response of graphene quantum dots by 100 to 1000 folds [44]. Because of its wide band gap $\mathrm{ZnO}$ is used in many UV optoelectronics applications [45]. UV responsivity of our RGO based photodetector is found to be better than many $\mathrm{ZnO}$ based detectors [20]. In our article, we have noticed that by controlling the $\mathrm{C} / \mathrm{O}$ ratio, MGB assisted photoresponse in RGO can reach a high value of 0.78 and $0.27 \mathrm{~A} . \mathrm{W}^{-1}$ under IR and UV irradiation, respectively at a source drain bias of $0.5 \mathrm{~V}$. Considering linear variation of photocurrent with voltage our devices show better responsivity and external quantum efficiency than most of the devices where graphene or RGO is the only active material. Also, rise and decay time constants are comparatively smaller which indicates a faster operation of our devices. During preparation of our article, we have come across an article where a responsivity of 3.10 $\mathrm{x} 10^{4} \mathrm{~A} . \mathrm{W}^{-1}$ has been achieved $\left(\mathrm{V}_{\mathrm{S}-\mathrm{D}}=5 \mathrm{~V}\right)$ in $3 \mathrm{D}$ nanoporous reduced graphene oxide [40]. Although the achieved responsivity value is very high it requires much costly instrumental setups, high temperature processes involving toxic chemicals and multiple steps with much longer preparation time. Also 3D nanoporous RGO based devices have much higher value of time constants indicating slower operation of these devices.

Most of the article on reduced graphene oxide based photodetectors lack of detailed mechanistic view of photodetection. In our article, photocurrent measurement with chopper clearly indicates photocurrent is photovoltaic in nature. Temperature-dependent photocurrent measurement indicates the presence of MGB which helps in higher photocurrent by gain mechanism. Also we have shown the variation of $\mathrm{EQE}$ with $\mathrm{C} / \mathrm{O}$ ratio of as-prepared RGOs and explained the underlining reason for superlinear behaviour. Interestingly, as photocurrent varies linearly with temperature RGO based photodetectors can be used as temperature sensor as well. 
Table 4: Characteristic values of some Graphene or RGO based infrared detectors.

\begin{tabular}{|c|c|c|c|c|c|c|c|}
\hline \multirow{2}{*}{$\begin{array}{l}\text { Acrtive Material } \\
\text { (special feature) }\end{array}$} & \multirow{2}{*}{$\begin{array}{c}\lambda \\
(\mathrm{nm})\end{array}$} & \multirow{2}{*}{$\begin{array}{l}\text { Bias } \\
\text { Voltage } \\
\text { (Volt) }\end{array}$} & \multicolumn{2}{|c|}{ Rise (s) } & \multicolumn{2}{|c|}{ Decay (s) } & \multirow{2}{*}{$\begin{array}{l}\text { Responsivity } \\
\left(\text { A. } W^{-1}\right)\end{array}$} \\
\hline & & & $\tau_{1}$ & $\tau_{2}$ & & $\tau_{2}$ & \\
\hline $\begin{array}{l}\text { Few Layer Graphene [10] } \\
\text { (wrinkled defects } \\
\text { induced) }\end{array}$ & 1550 & - & & & 5 & 55 & $12.5 * 10^{-6}$ \\
\hline $\begin{array}{l}\text { Graphene [41] } \\
\text { (asymmetric elecrode) }\end{array}$ & 1550 & $\begin{array}{l}\mathrm{V}_{\mathrm{SD}}=0.4 \\
\mathrm{~V}_{\mathrm{G}}=15\end{array}$ & & & & & $6.1 * 10^{-3}$ \\
\hline $\begin{array}{l}\text { Graphene } \\
\text { (microcavity-integrated) }\end{array}$ & 855 & 2 & & & & & $21 * 10^{-3}$ \\
\hline $\begin{array}{l}\text { Bilayer Graphene } \\
\text { (coupled Si waveguide) }\end{array}$ & 1550 & 1 & & & & & 0.108 \\
\hline \multirow{2}{*}{$\begin{array}{l}\mathrm{RGO}[31,46] \\
\text { (hydrazine hydrate } \\
\text { reduction) }\end{array}$} & 1550 & 2 & 2 & 26 & 2 & 29 & $4 * 10^{-3}$ \\
\hline & 360 & 1 & 1800 & & 2100 & & 0.12 \\
\hline $\begin{array}{l}\text { RGO [47] } \\
\text { (Solar exfoliated reduced } \\
\text { graphene oxide) }\end{array}$ & IR Lamp & 1 & & & & & 0.8 \\
\hline $\begin{array}{l}\text { RGO [43] } \\
\text { (thermally reduced at } \\
170^{\circ} \mathrm{C} \text { ) }\end{array}$ & IR Lamp & 2 & 240 & & 300 & & 0.55 \\
\hline $\begin{array}{l}\text { RGO }[30] \\
\text { (defects controlled) }\end{array}$ & 895 & 19 & 2 & 20 & 6 & 90 & 0.7 \\
\hline \multirow{2}{*}{$\begin{array}{l}\text { RGO } 4 \text { (This Article) } \\
\text { ( } C / O \text { ratio and } M G B \\
\text { assisted) }\end{array}$} & 1550 & 0.5 & 0.09 & 4.26 & 0.95 & 8.52 & 0.78 \\
\hline & 325 & 0.5 & 0.26 & 2.23 & 0.25 & 4.07 & 0.268 \\
\hline
\end{tabular}




\section{Conclusions}

Solvothermal reduction of GO in ethylene glycol is efficient and amount of reduction can be tuned by controlling the reduction time. Responsivity and quantum efficiency values of our RGO based photodetectors are much higher than most of the graphene or RGO based photodetectors. This could be due to a proper combination of increased absorption, formation of MGB and better hopping transport in prepared RGOs. Responses of our photodetector are also quite faster. One of the interesting outcomes is that RGO based photodetector show potential for temperature sensor application.

Conflicts of Interest: The authors declare that they have no conflict of interest.

\section{References:}

1. A. Rogalski, Acta Phys. Pol. A 116, 389-406 (2009).

2. R. B. Taylor, P. E. Burrows and S. R. Forrest, IEEE Photonic. Tech. L. 9, 365-367 (1997).

3. M. Kopytko, J. Wróbel, K. Jóźwikowski, A. Rogalski, J. Antoszewski, N. Akhavan, G. Umana-Membreno, L. Faraone and C. Becker, J. Electron. Mater. 44, 158-166 (2015).

4. J. M. Martin, J. L. Hernández, L. Adell, A. Rodriguez and F. Lopez, Semicond. Sci. Technol. 11, 1740 (1996).

5. R. Nair, P. Blake, A. Grigorenko, K. Novoselov, T. Booth, T. Stauber, N. Peres and A. Geim, Science 320, 1308-1308 (2008).

6. $\quad$ M. Breusing, C. Ropers and T. Elsaesser, Phys. Rev. Lett. 102, 086809 (2009).

7. P. A. George, J. Strait, J. Dawlaty, S. Shivaraman, M. Chandrashekhar, F. Rana and M. G. Spencer, Nano Lett. 8, 4248-4251 (2008).

8. T. J. Echtermeyer, L. Britnell, P. K. Jasnos, A. Lombardo, R. V. Gorbachev, A. N. Grigorenko, A. K. Geim, A. C. Ferrari and K. S. Novoselov, Nat. Commun. 2, 458 (2011). 
9. M. Furchi, A. Urich, A. Pospischil, G. Lilley, K. Unterrainer, H. Detz, P. Klang, A. M. Andrews, W. Schrenk, G. Strasser and T. Mueller, Nano Lett. 12, 2773-2777 (2012).

10. P. Gowda, T. Sakorikar, S. K. Reddy, D. B. Ferry and A. Misra, ACS Appl. Mater. Inter. 6, 7485-7490 (2014).

11. J. M. Yoo, J. H. Kang and B. H. Hong, Chem. Soc. Rev. 44, 4835-4852 (2015).

12. S. K. Bhunia and N. R. Jana, ACS Appl. Mater. Inter. 6, 20085-20092 (2014).

13. A. Saito, H. Kinoshita, K.-i. Shimizu and Y. Nishina, Bull. Chem. Soc. Jpn. 89, 67-73 (2015).

14. S. Murphy, L. Huang and P. V. Kamat, J. Phys. Chem. C 117, 4740-4747 (2013).

15. V. Chandra, J. Park, Y. Chun, J. W. Lee, I.-C. Hwang and K. S. Kim, ACS Nano 4, 39793986 (2010).

16. Y. Xu, G. Shi and X. Duan, Acc. Chem. Res. 48, 1666-1675 (2015).

17. M. B. Zakaria, C. Li, Q. Ji, B. Jiang, S. Tominaka, Y. Ide, J. P. Hill, K. Ariga and Y. Yamauchi, Angew. Chem. Int. Ed. 55, 8426-8430 (2016).

18. H. Yang, Y. Cao, J. He, Y. Zhang, B. Jin, J.-L. Sun, Y. Wang and Z. Zhao, Carbon 115, 561-570 (2017).

19. D. Alsaedi, M. Irannejad, K. H. Ibrahim, A. Almutairi, O. Ramahi and M. Yavuz, J. Mater. Chem. C 5, 882-888 (2017).

20. F. Teng, L. Zheng, K. Hu, H. Chen, Y. Li, Z. Zhang and X. Fang, J. Mater. Chem. C 4, 8416-8421 (2016).

21. H. Chen, H. Liu, Z. Zhang, K. Hu and X. Fang, Adv. Mater. 28, 403-433 (2016).

22. W. S. Hummers Jr and R. E. Offeman, J. Am. Chem. Soc. 80, 1339-1339 (1958).

23. S. Ida, Bull. Chem. Soc. Jpn. 88, 1619-1628 (2015).

24. S. Park, J. An, J. R. Potts, A. Velamakanni, S. Murali and R. S. Ruoff, Carbon 49, 30193023 (2011).

25. S. Some, Y. Kim, E. Hwang, H. Yoo and H. Lee, Chem. Commun. 48, 7732-7734 (2012).

26. A. C. Ferrari, Solid State Commun. 143, 47-57 (2007).

27. G. Srinivas, Y. Zhu, R. Piner, N. Skipper, M. Ellerby and R. Ruoff, Carbon 48, 630-635 (2010).

28. F. Tuinstra and J. L. Koenig, J. Chem. Phys. 53, 1126-1130 (1970).

29. H. Kind, H. Yan, B. Messer, M. Law and P. Yang, Adv. Mater. 14, 158 (2002). 
30. H. Chang, Z. Sun, M. Saito, Q. Yuan, H. Zhang, J. Li, Z. Wang, T. Fujita, F. Ding, Z. Zheng, F. Yan, H. Wu, M. Chen and Y. Ikuhara, ACS Nano 7, 6310-6320 (2013).

31. B. Chitara, L. Panchakarla, S. B. Krupanidhi and C. N. R. Rao, Adv. Mater. 23, 54195424 (2011).

32. S. Bae, H. Kim, Y. Lee, X. Xu, J.-S. Park, Y. Zheng, J. Balakrishnan, T. Lei, H. Ri Kim, Y. I. Song, Y.-J. Kim, K. S. Kim, B. Ozyilmaz, J.-H. Ahn, B. H. Hong and S. Iijima, Nat. Nanotechnol. 5, 574-578 (2010).

33. A. Mathkar, D. Tozier, P. Cox, P. Ong, C. Galande, K. Balakrishnan, A. Leela Mohana Reddy and P. M. Ajayan, J. Phys. Chem. Lett. 3, 986-991 (2012).

34. T. Stauber, N. Peres and F. Guinea, Physical Review B 76, 205423 (2007).

35. T. Wehling, M. Katsnelson and A. Lichtenstein, Phys. Rev. B 80, 085428 (2009).

36. M. Vozmediano, M. López-Sancho, T. Stauber and F. Guinea, Phys. Rev. B 72, 155121 (2005).

37. B. Y. Zhang, T. Liu, B. Meng, X. Li, G. Liang, X. Hu and Q. J. Wang, Nat. Commun. 4, 1811 (2013).

38. H. Wei, Y. Fang, Y. Yuan, L. Shen and J. Huang, Adv. Mater. 27, 4975-4981 (2015).

39. R.-S. Chen, H.-Y. Chen, C.-Y. Lu, K.-H. Chen, C.-P. Chen, L.-C. Chen and Y.-J. Yang, Appl. Phys. Lett. 91, 223106 (2007).

40. Y. Ito, W. Zhang, J. Li, H. Chang, P. Liu, T. Fujita, Y. Tan, F. Yan and M. Chen, $A d v$. Funct. Mater. 26, 1271-1277 (2016).

41. T. Mueller, F. Xia and P. Avouris, Nat. Photonics 4, 297-301 (2010).

42. X. Gan, R.-J. Shiue, Y. Gao, I. Meric, T. F. Heinz, K. Shepard, J. Hone, S. Assefa and D. Englund, Nat. Photonics 7, 883-887 (2013).

43. F. A. Chowdhury, T. Mochida, J. Otsuki and M. S. Alam, Chem. Phys. Lett. 593, 198-203 (2014).

44. Q. Zhang, J. Jie, S. Diao, Z. Shao, Q. Zhang, L. Wang, W. Deng, W. Hu, H. Xia and X. Yuan, ACS Nano 9, 1561-1570 (2015).

45. A. S. Elahi and M. Ghoranneviss, J. Mater. Sci.: Mater. Electron. 28, 1659-1666 (2017).

46. B. Chitara, S. Krupanidhi and C. Rao, Appl. Phys. Lett. 99, 113114 (2011).

47. P. Sahatiya, S. K. Puttapati, V. V. Srikanth and S. Badhulika, Flex. Print. Electron. 1, 025006 (2016). 
Cover Art

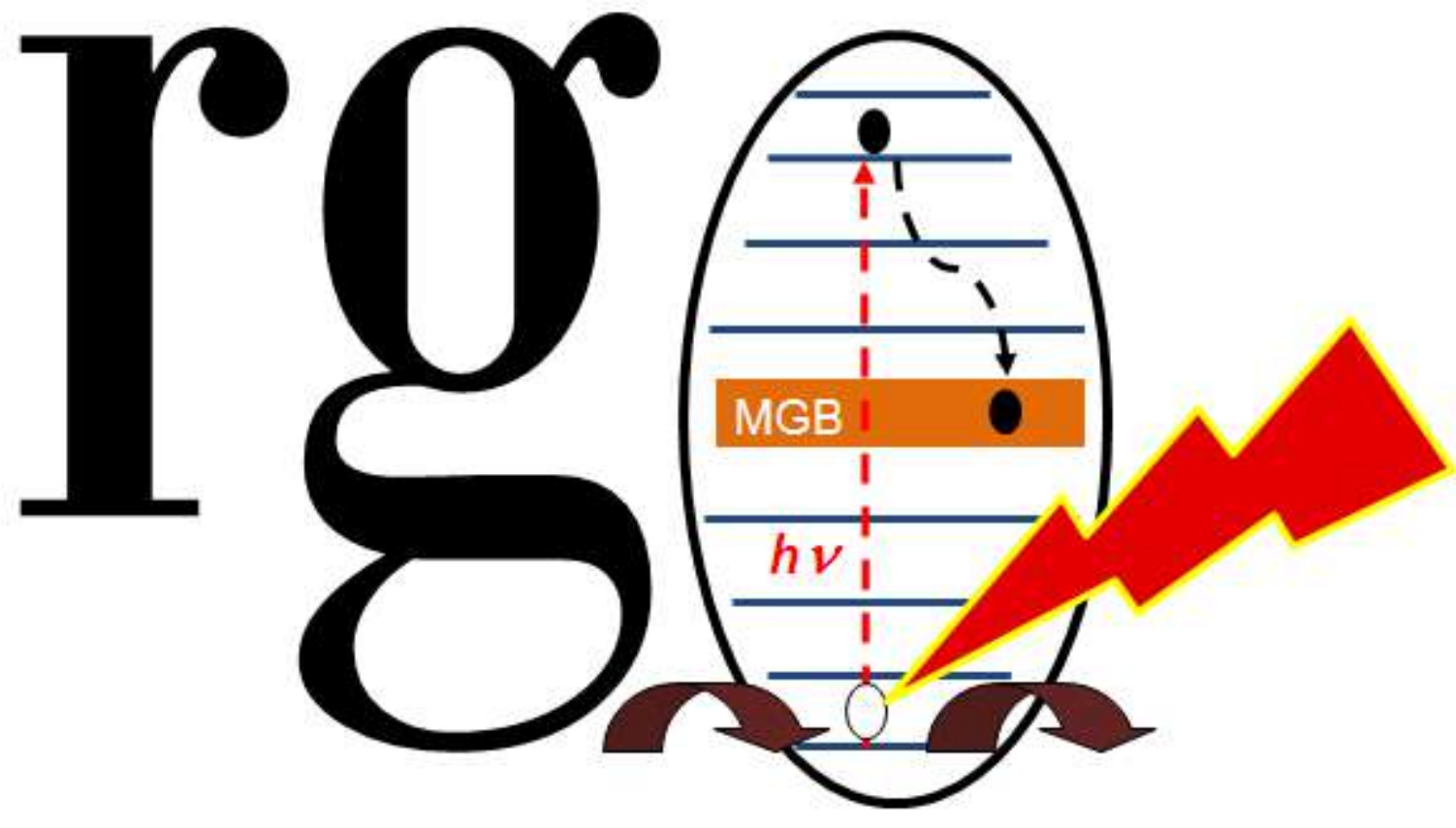


Supporting Information

\section{Mechanistic View on Efficient Photodetection by Solvothermally Reduced Graphene Oxide}

Mustaque A Khan, ${ }^{\dagger}$ Karuna K Nanda ${ }^{\dagger}$ and Saluru B Krupanidhi ${ }^{*}{ }^{\dagger}$

${ }^{\dagger}$ Materials Research Centre, Indian Institute of Science, Bangalore 560012, India

\section{Corresponding Author}

*E-mail: sbk@mrc.iisc.ernet.in 


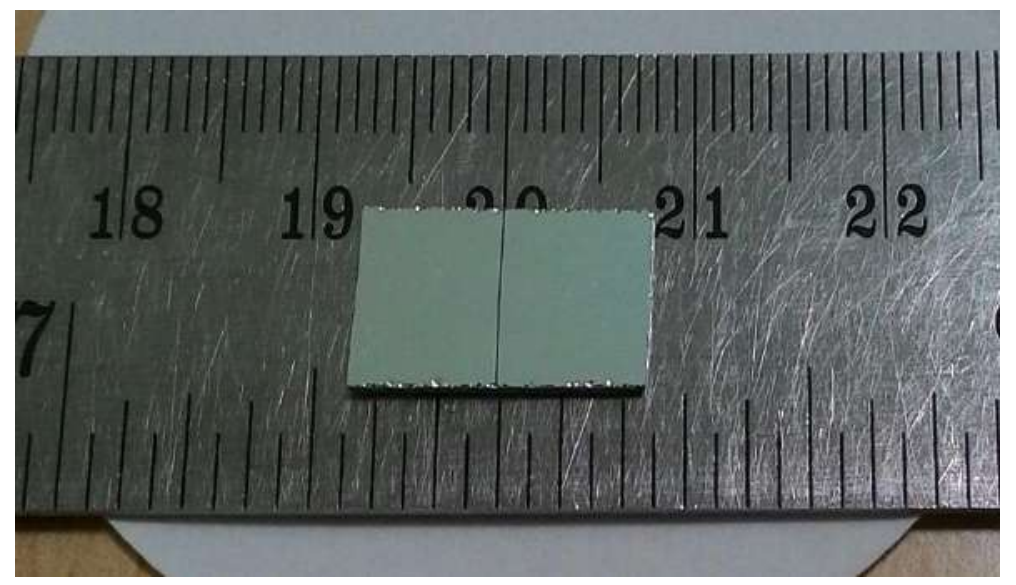

Fig. S1: Silver electrodes on a quartz substrate $\left(\sim 0.7 \times 1 \mathrm{~cm}^{2}, 200 \mathrm{~nm}\right.$ thick electrodes deposited by thermal evaporation and in between gap is $95 \mu \mathrm{m}$.)

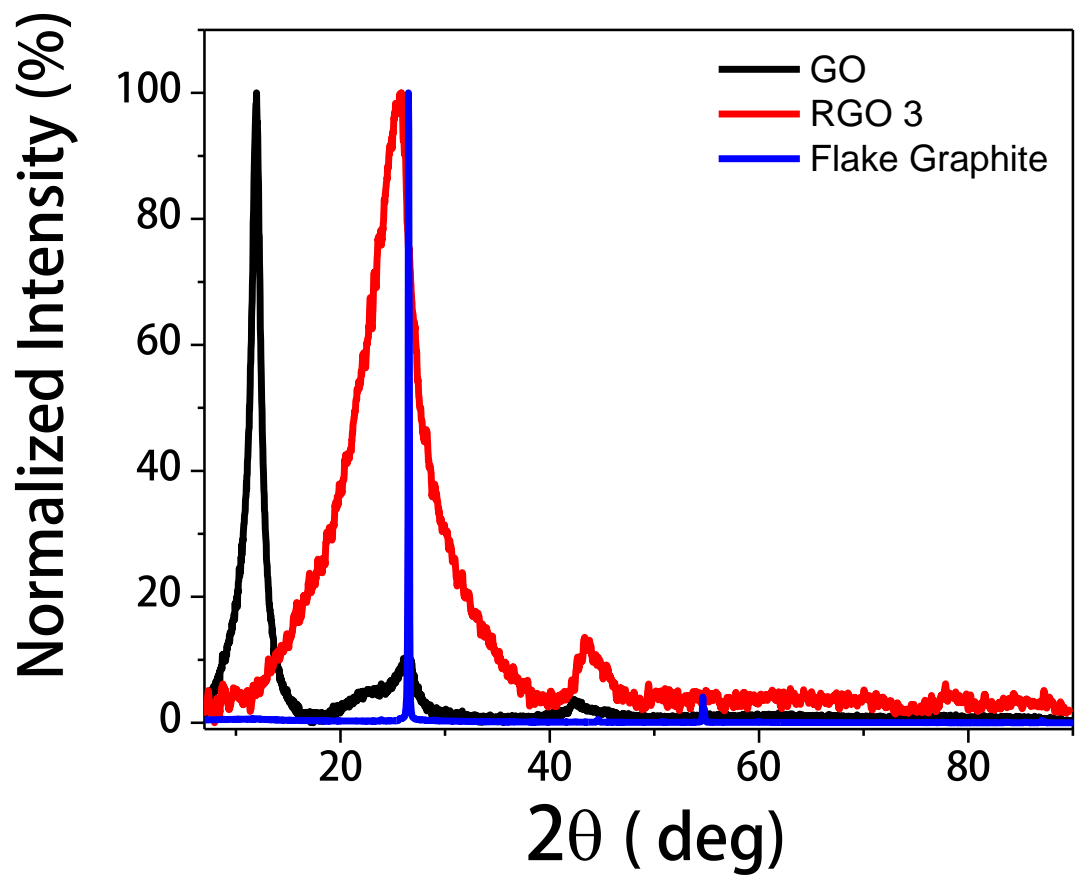

Fig. S2: X-ray diffraction spectra of graphite flake, GO and RGO. 


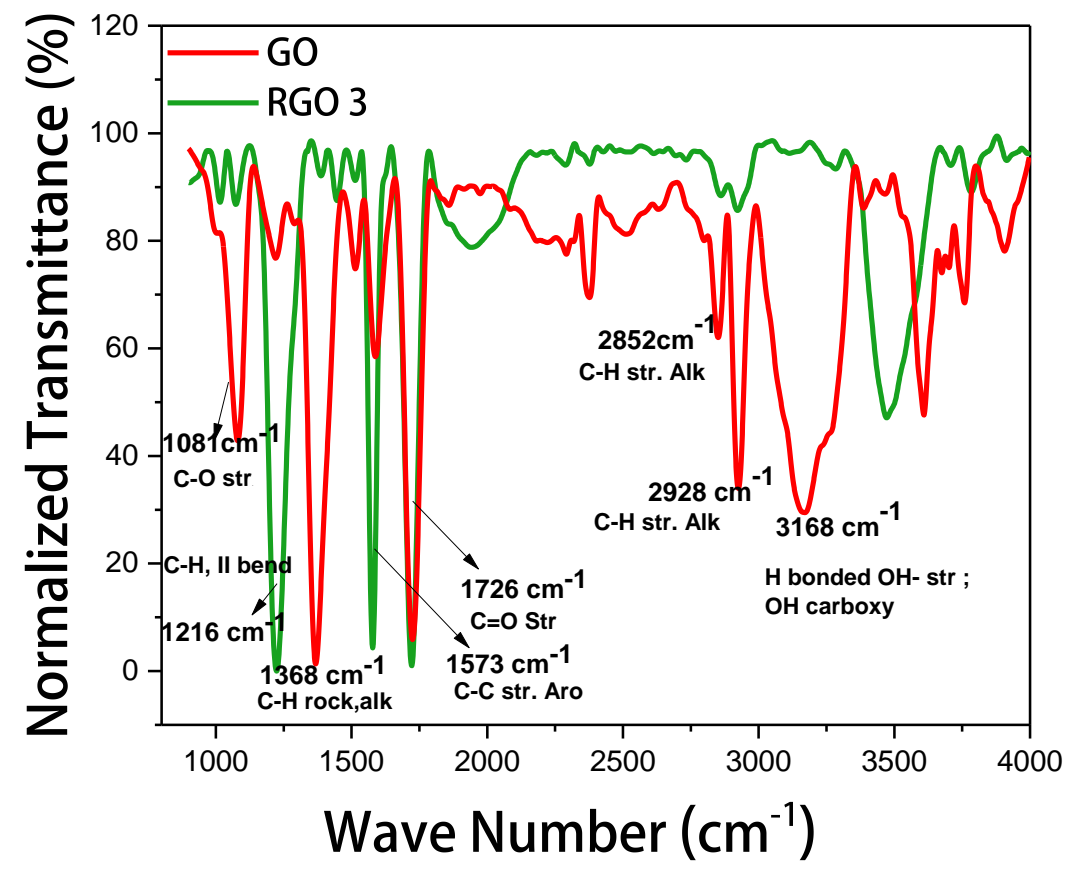

Fig. S3: Infrared transmission spectra of GO and RGO3.

(a)

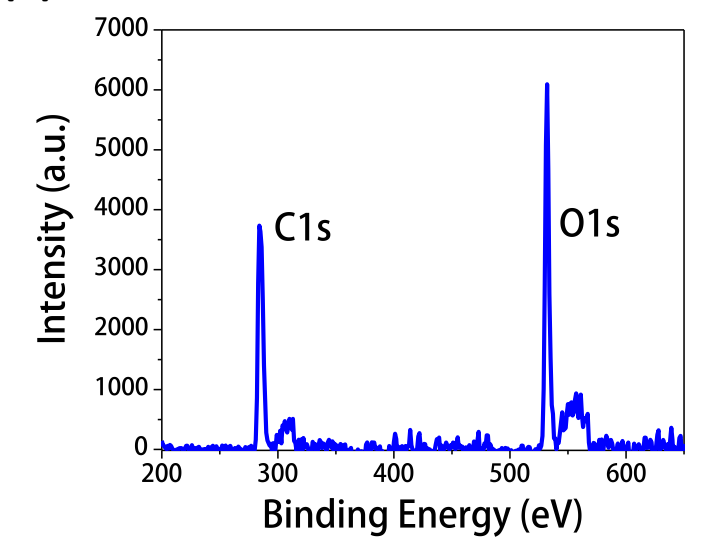

(b)

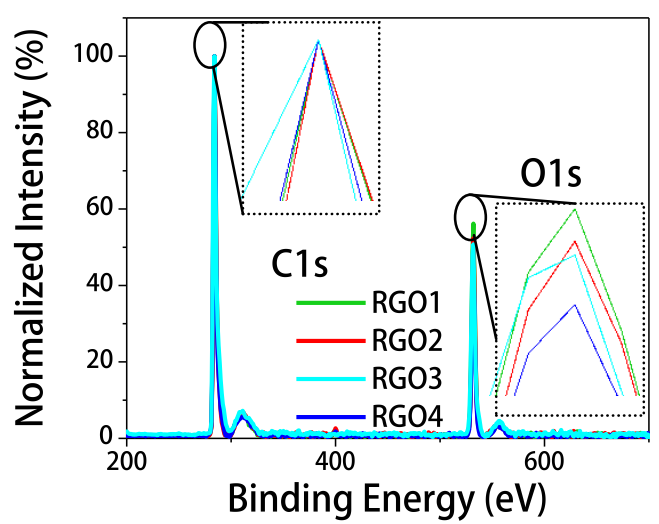

Fig. S4: (a), (b) XPS survey spectrum of GO and RGO, respectively. 
(a)

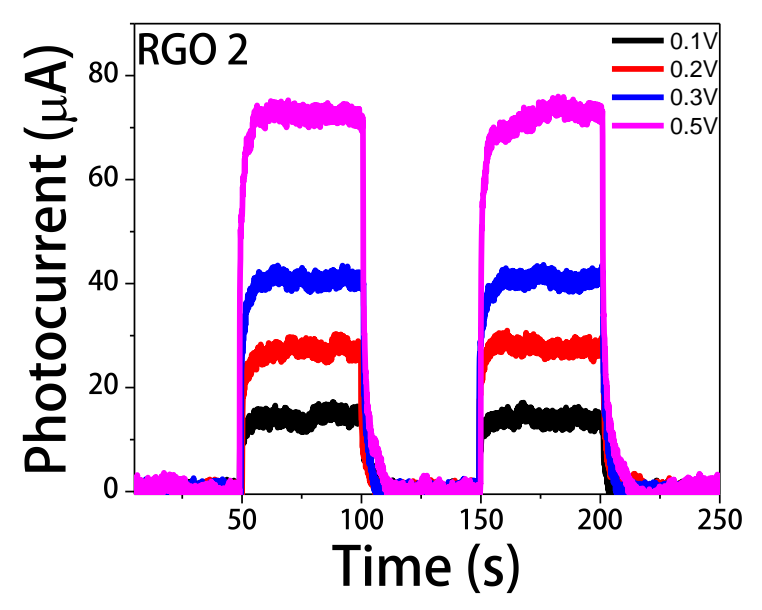

(b)

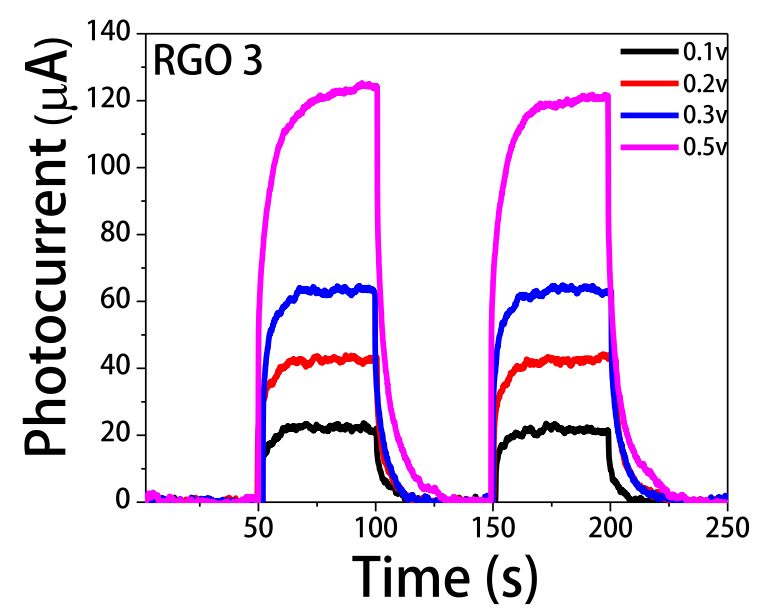

(c)

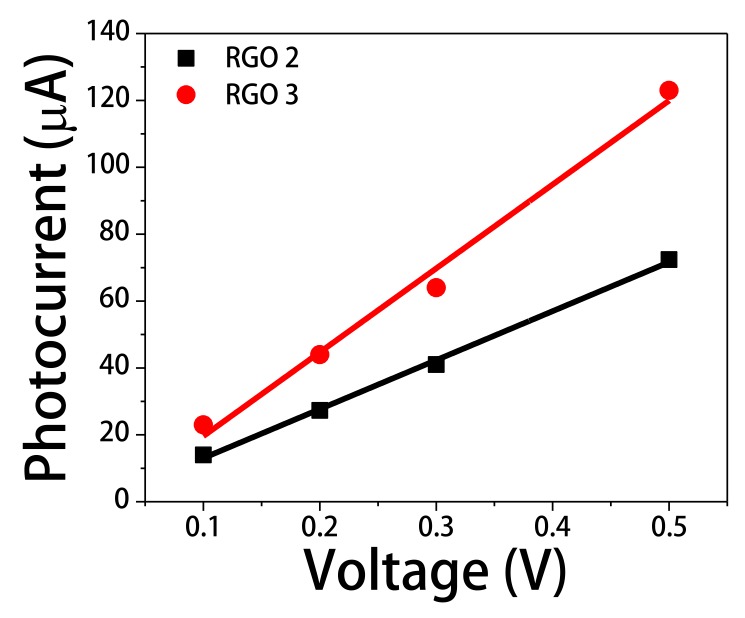

Fig. S5: (a), (b) Temporal photoresponse of RGO 2 and RGO 3 respectively at different voltages and at a constant intensity of $79 \mathrm{~mW} \cdot \mathrm{cm}^{-2}(\lambda=1550 \mathrm{~nm})$. (c) Variation of photocurrent with voltage for different RGOs. 
(a)

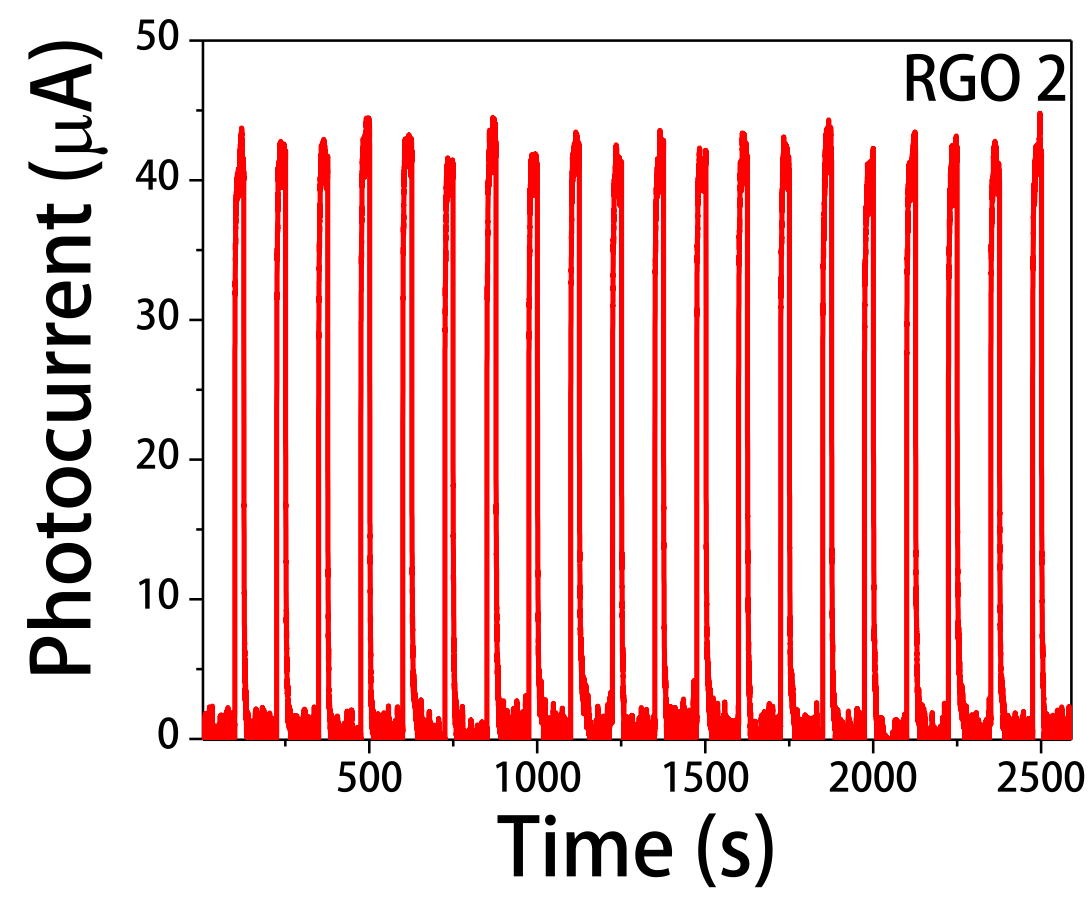

(b)

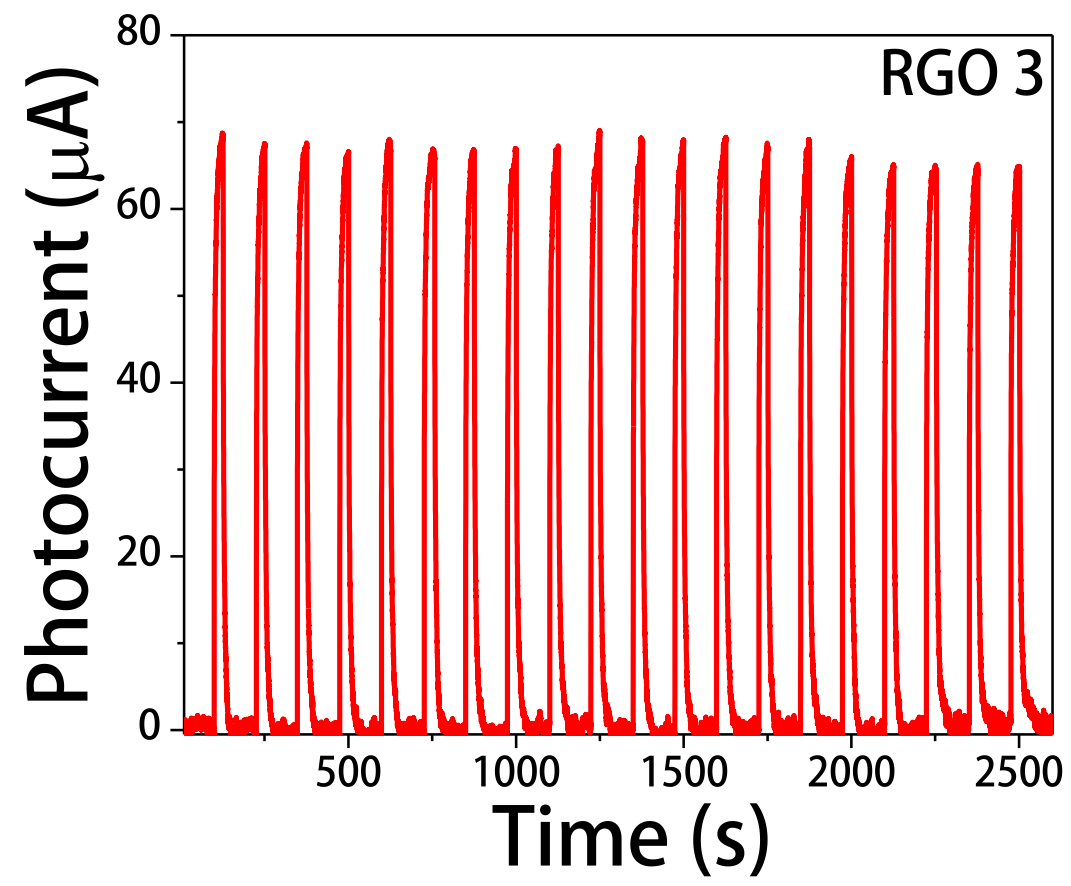

Fig. S6: (a), (b) On-off measurement over 20 cycles for RGO 2 and RGO 3 respectively ( $\lambda$ $=1550 \mathrm{~nm})$. 
(a)

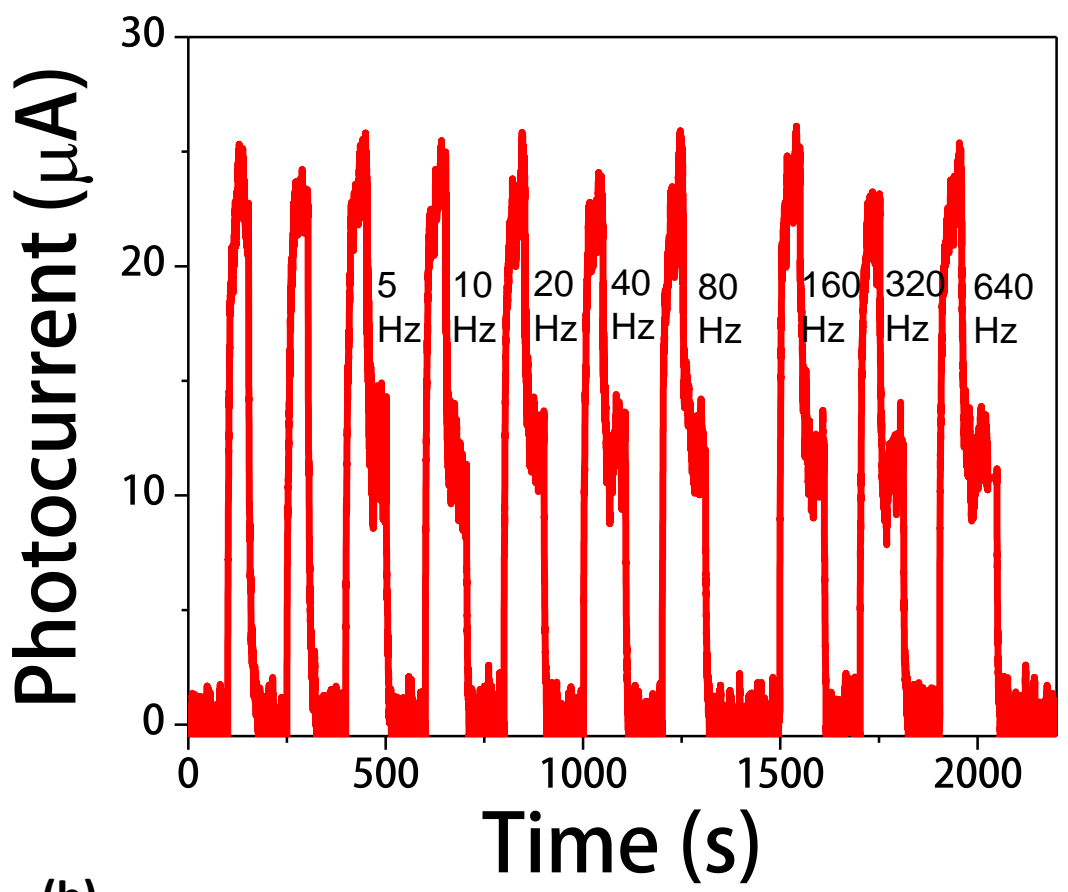

(b)

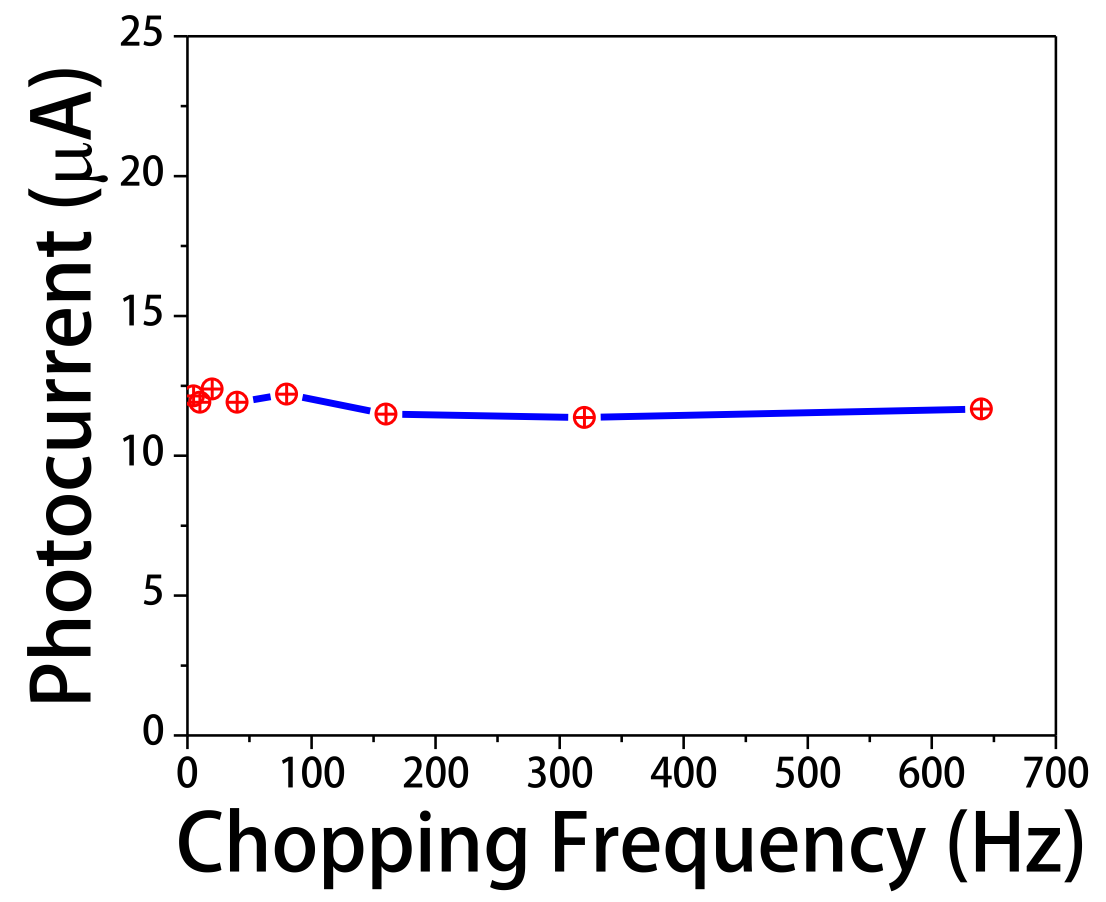

Fig. S7: (a) Temporal photoresponse with different chopping frequency, (b) variation of photocurrent with chopping frequency $(\lambda=1550 \mathrm{~nm})$. 
(a)

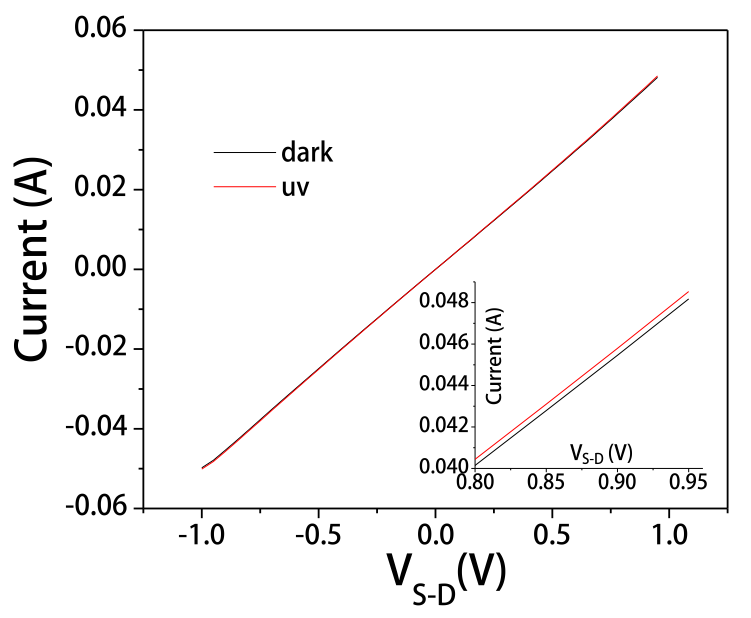

(b)

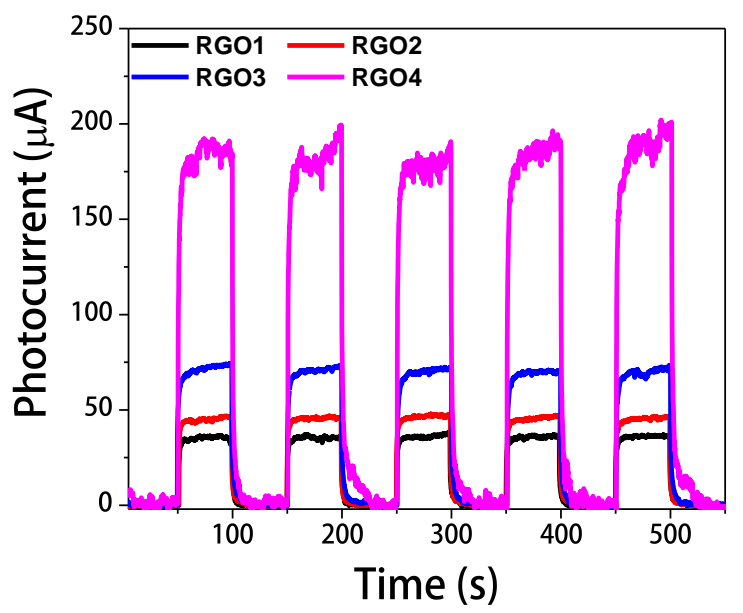

(c)

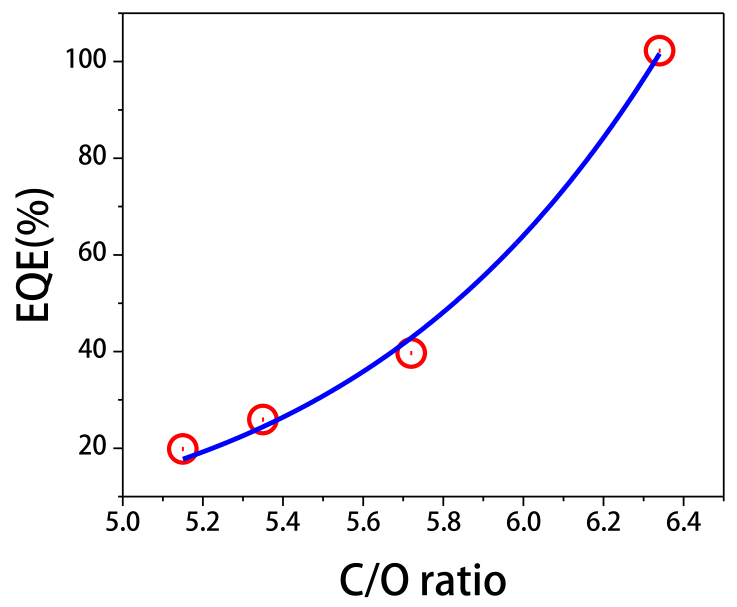

Fig. S8: (a) I-V characteristic of RGO 4 (b) Temporal photoresponse of different RGOs at bias of $0.5 \mathrm{~V}, \lambda=325 \mathrm{~nm}$ and $\mathrm{I}_{\mathrm{L}}=519.6 \mathrm{~mW} . \mathrm{cm}^{-2}$, and (c) Variation of EQE with C/O ratio of RGOs $(\lambda=325 \mathrm{~nm})$. 


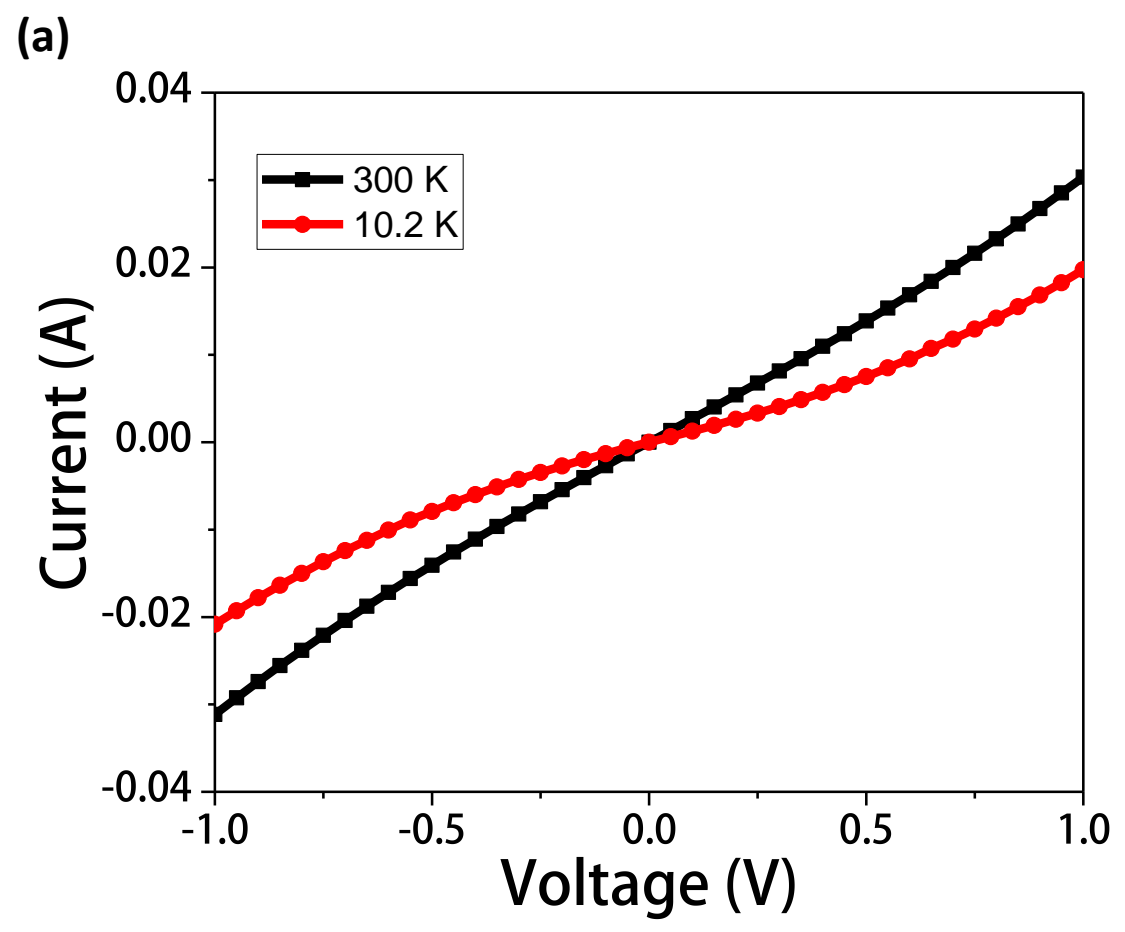

(b)

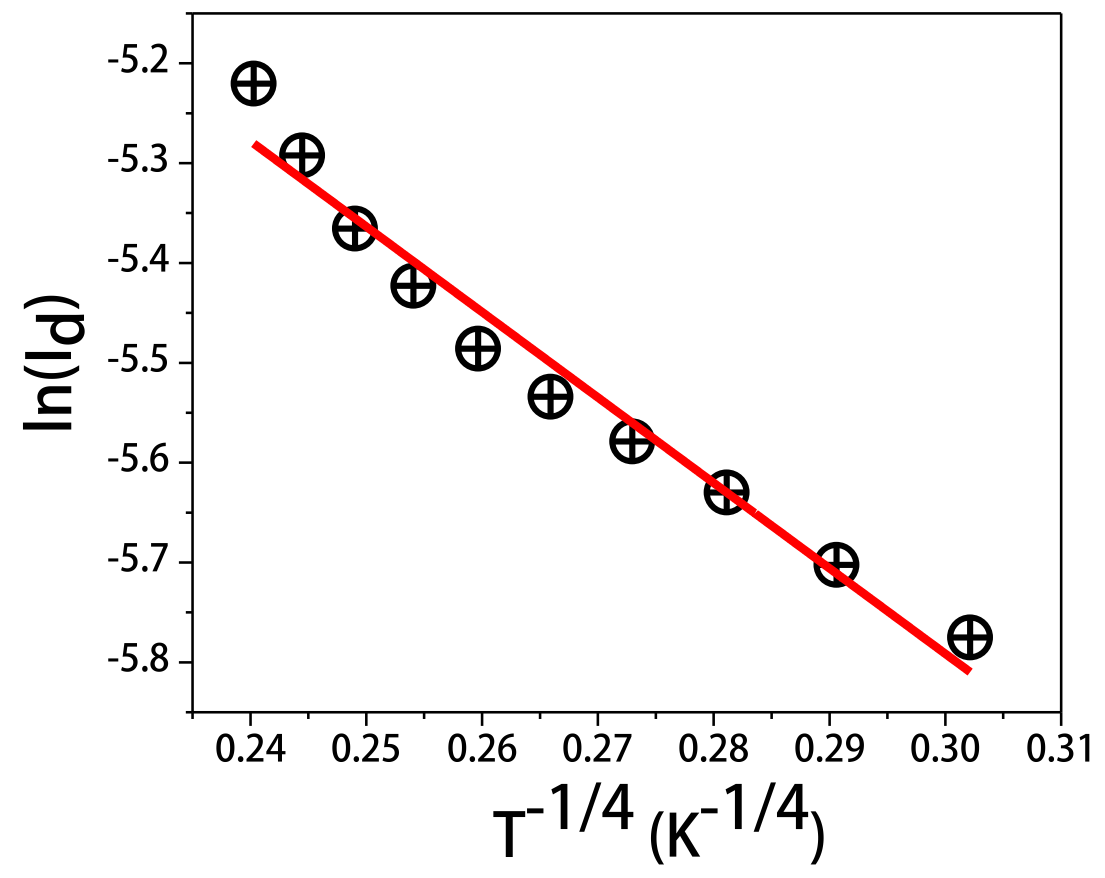

Fig. S9: (a) I-V characteristics at low and room temperature (b) dark current variation with temperature at $0.2 \mathrm{~V}$. 
(a)

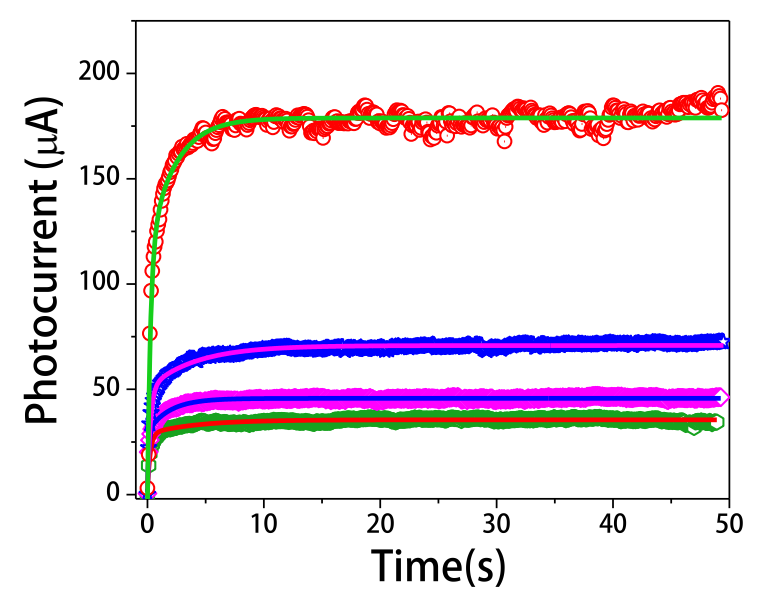

(b)

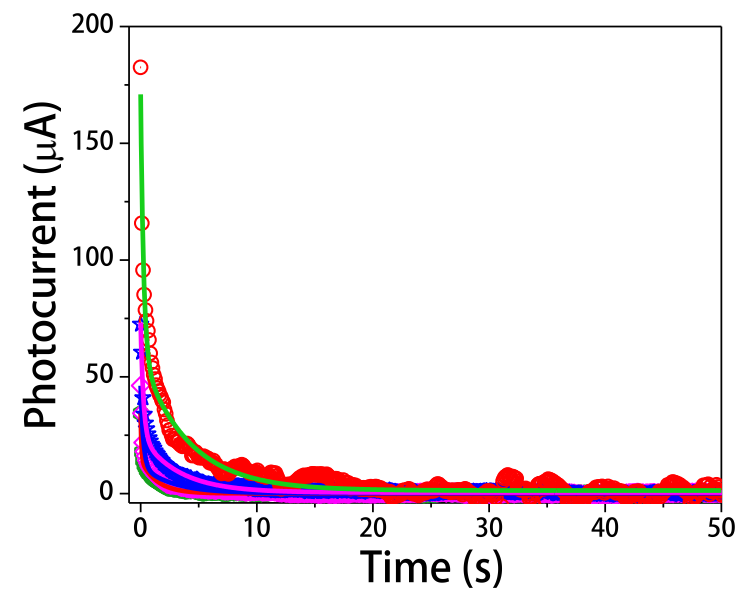

Fig. S10: (a) Rise and (b) decay of photocurrent at an intensity of $519.6 \mathrm{~mW} \cdot \mathrm{cm}^{-2}$ at $0.5 \mathrm{~V}$ bias $(\lambda=325 \mathrm{~nm})$ and their exponential fittings.

Table S1: Time constants for rise and decay of photocurrent for UV (325 nm) irradiation of $519.6 \mathrm{~mW} . \mathrm{cm}^{-2}$ at $0.5 \mathrm{~V}$ applied bias.

\begin{tabular}{|c|c|c|c|c|}
\hline Sample & \multicolumn{2}{|c|}{ Rise } & \multicolumn{2}{c|}{ Decay } \\
& \multicolumn{2}{|c|}{$\tau_{1}$} & $\tau_{2}$ & $\tau_{2}$ \\
\hline RGO 1 & $0.23 \pm 0.01$ & $4.13 \pm 0.26$ & $0.07 \pm 0.01$ & $1.40 \pm 0.03$ \\
\hline RGO 2 & $0.12 \pm 0.01$ & $1.86 \pm 0.05$ & $0.22 \pm 0.01$ & $2.70 \pm 0.07$ \\
\hline RGO 3 & $0.26 \pm 0.01$ & $4.06 \pm 0.12$ & $0.24 \pm 0.01$ & $3.26 \pm 0.06$ \\
\hline RGO 4 & $0.26 \pm 0.02$ & $2.23 \pm 0.14$ & $0.25 \pm 0.01$ & $4.07 \pm 0.15$ \\
\hline
\end{tabular}

